\title{
Retrievals of formaldehyde from ground-based FTIR and MAX-DOAS observations at the Jungfraujoch station and comparisons with GEOS-Chem and IMAGES model simulations
}

\author{
B. Franco ${ }^{1}$, F. Hendrick ${ }^{2}$, M. Van Roozendael ${ }^{2}$, J.-F. Müller ${ }^{2}$, T. Stavrakou ${ }^{2}$, E. A. Marais ${ }^{3}$, B. Bovy ${ }^{1}$, W. Bader ${ }^{1}$, \\ C. Fayt ${ }^{2}$, C. Hermans ${ }^{2}$, B. Lejeune ${ }^{1}$, G. Pinardi ${ }^{2}$, C. Servais ${ }^{1}$, and E. Mahieu ${ }^{1}$ \\ ${ }^{1}$ Institute of Astrophysics and Geophysics of the University of Liège, Liège, Belgium \\ ${ }^{2}$ Belgian Institute for Space Aeronomy (BIRA-IASB), Brussels, Belgium \\ ${ }^{3}$ School of Engineering and Applied Sciences, Harvard University, Cambridge, MA, USA
}

Correspondence to: B. Franco (bruno.franco@ulg.ac.be)

Received: 5 September 2014 - Published in Atmos. Meas. Tech. Discuss.: 23 October 2014

Revised: 25 March 2015 - Accepted: 27 March 2015 - Published: 15 April 2015

\begin{abstract}
As an ubiquitous product of the oxidation of many volatile organic compounds (VOCs), formaldehyde (HCHO) plays a key role as a short-lived and reactive intermediate in the atmospheric photo-oxidation pathways leading to the formation of tropospheric ozone and secondary organic aerosols. In this study, HCHO profiles have been successfully retrieved from ground-based Fourier transform infrared (FTIR) solar spectra and UV-visible Multi-AXis Differential Optical Absorption Spectroscopy (MAX-DOAS) scans recorded during the July 2010-December 2012 time period at the Jungfraujoch station (Swiss Alps, $46.5^{\circ} \mathrm{N}, 8.0^{\circ} \mathrm{E}$, $3580 \mathrm{~m}$ a.s.l.). Analysis of the retrieved products has revealed different vertical sensitivity between both remote sensing techniques. Furthermore, $\mathrm{HCHO}$ amounts simulated by two state-of-the-art chemical transport models (CTMs), GEOSChem and IMAGES v2, have been compared to FTIR total columns and MAX-DOAS $3.6-8 \mathrm{~km}$ partial columns, accounting for the respective vertical resolution of each ground-based instrument. Using the CTM outputs as the intermediate, FTIR and MAX-DOAS retrievals have shown consistent seasonal modulations of HCHO throughout the investigated period, characterized by summertime maximum and wintertime minimum. Such comparisons have also highlighted that FTIR and MAX-DOAS provide complementary products for the HCHO retrieval above the Jungfraujoch station. Finally, tests have revealed that the updated IR parameters from the HITRAN 2012 database have a cumulative ef-
\end{abstract}

fect and significantly decrease the retrieved $\mathrm{HCHO}$ columns with respect to the use of the HITRAN 2008 compilation.

\section{Introduction}

Formaldehyde (HCHO) is the most abundant organic carbonyl compound in the remote troposphere (Hak et al., 2005, and references therein). Being predominantly a high-yield product of oxidation by hydroxyl radicals $(\mathrm{OH})$ of most of the primary volatile organic compounds (VOCs) emitted either naturally or by human activities, HCHO is ubiquitous throughout the atmosphere. It is also directly emitted in a small fraction from biogenic (e.g., vegetation), pyrogenic (mainly biomass burning) and anthropogenic (e.g., industrial emissions) sources (e.g., Carlier et al., 1986; Lee et al., 1997; Hak et al., 2005; Herndon et al., 2005; Fu et al., 2007; De Smedt et al., 2010). Long-lived VOCs such as methane $\left(\mathrm{CH}_{4}\right)$ contribute to the background levels of HCHO. However, the spatial variability of HCHO concentration is primarily associated with the oxidation of reactive non-methane VOCs of biogenic (e.g., isoprene) or anthropogenic (e.g., butane) origin. At low nitric oxide (NO) concentrations, intermediate compounds such as methyl hydroperoxide $\left(\mathrm{CH}_{3} \mathrm{OOH}\right)$ are formed which are partly removed by deposition, thereby reducing $\mathrm{HCHO}$ formation.

Formaldehyde has a very short midday lifetime on the order of a few hours (Logan et al., 1981; Possanzini et al., 
2002). Its main removal pathways take place by photolysis and oxidation by $\mathrm{OH}$ radicals, with both loss processes yielding carbon monoxide $(\mathrm{CO})$ and hydroperoxyl radicals $\left(\mathrm{HO}_{2}\right)$, so that $\mathrm{HCHO}$ affects the global $\mathrm{CO}$ budget and the oxidative capacity of the atmosphere. Losses of HCHO by dry and wet deposition near the surface are generally less significant (Atkinson, 2000). Moreover, $\mathrm{HCHO}$ is an important intermediate in the $\mathrm{VOC}-\mathrm{HO}_{x}$ (hydrogen oxides)- $\mathrm{NO}_{x}$ (nitrogen oxides) chemistry (Houweling et al., 1998; Hak et al., 2005; Kanakidou et al., 2005), making it a key component in the global catalytic cycle responsible for generating or destroying tropospheric ozone $\left(\mathrm{O}_{3}\right)$, depending on the $\mathrm{NO}_{x}$ levels (Fried et al., 1997; Lee et al., 1998; Tan et al., 2001).

Recently, total FTIR (Fourier transform infrared) and partial UV-visible MAX-DOAS (Multi-AXis Differential Optical Absorption Spectroscopy) columns of HCHO derived from ground-based remote sensing measurements have been used to evaluate HCHO observations obtained from SCIAMACHY (SCanning Imaging Absorption spectroMeter for Atmospheric CHartographY), GOME (Global Ozone Monitoring Experiment) and ACE-FTS (Atmospheric Chemistry Experiment Fourier transform spectrometer) spacebased sensors (e.g., Wittrock et al., 2006; Jones et al., 2009; Vigouroux et al., 2009; Viatte et al., 2014). Such studies reported an overall consistency between satellite HCHO observations and ground-based FTIR and MAX-DOAS measurements at a number of sites influenced by biomass burning (Wittrock et al., 2006; Jones et al., 2009; Vigouroux et al., 2009) or urban sources of pollution (Wittrock et al., 2006). In addition, Vigouroux et al. (2009) successfully compared FTIR and MAX-DOAS observations, HCHO columns from SCIAMACHY nadir satellite and simulations by the global CTM (chemistry transport model) IMAGES v2 (Intermediate Model of Annual and Global Evolution of Species) at Reunion Island $\left(20.9^{\circ} \mathrm{S}, 55.5^{\circ} \mathrm{E}\right)$.

In this study, we report parallel $\mathrm{HCHO}$ measurements performed at the high-altitude research station of Jungfraujoch (Swiss Alps), part of the NDACC (Network for the Detection of Atmospheric Climate Change; see http://www.ndacc.org), using both ground-based high-resolution FTIR and MAXDOAS instruments. This work presents the first intercomparison of ground-based FTIR and MAX-DOAS HCHO observations carried out at a high-altitude, dry and weakly polluted site (Zander et al., 2008). The Jungfraujoch station contrasts with, e.g., the sea-level Reunion Island site where $\mathrm{HCHO}$ total columns are influenced by large precursor emissions originating from biogenic and pyrogenic sources in southern Africa and Madagascar (Vigouroux et al., 2009). The combination of elevation, weakly polluted conditions and the strong vertical gradient of $\mathrm{HCHO}$ concentration in the lower troposphere contributes to reducing the solar infrared absorption of $\mathrm{HCHO}$ at the Jungfraujoch station and makes it very challenging to retrieve.

FTIR and MAX-DOAS measurements are not directly comparable given their respective vertical resolution and sen- sitivity, but with this work we show that both techniques are essentially complementary for $\mathrm{HCHO}$ retrieval above Jungfraujoch. Therefore we use two state-of-the art threedimensional global CTMs, GEOS-Chem (v9-01-03; Bey et al., 2001) and IMAGES v2 (Stavrakou et al., 2013), for intercomparing FTIR total columns and MAX-DOAS partial columns of HCHO over the entire July 2010-December 2012 time period. The HCHO columns and concentrations simulated by the CTMs are compared successively to the groundbased data sets, taking into account the vertical sensitivity of each remote sensing instrument by applying their respective averaging kernels.

This work also aims at implementing and validating an optimized FTIR retrieval strategy for HCHO above Jungfraujoch as a preparation for further studies. Indeed, it is worth mentioning that FTIR solar spectra exploitable for the retrieval of HCHO are actually available at the Jungfraujoch station since the beginning of 1988. Using the FTIR retrieval strategy implemented and validated in the present study, all these solar spectra spanning the 1988-2014 time period are currently being processed in an ongoing work in order to produce long-term record of $\mathrm{HCHO}$ and investigate its interannual variability above Jungfraujoch. Finally, groundbased HCHO measurements are increasingly required to validate satellite observations such as SCIAMACHY, GOME, ACE-FTS and TROPOMI (TROPOspheric Monitoring Instrument).

The measurement site, instrumental setups, investigated data sets and ground-based retrieval strategies for the Jungfraujoch station are described in Sect. 2. A short description of the GEOS-Chem and IMAGES models as well as of the simulations performed in the framework of this study is also given in Sect. 2. Section 3 presents the characterization of the FTIR and MAX-DOAS geophysical products, including a detailed error budget for each ground-based data set. Section 4 reports the results of the HCHO retrievals above Jungfraujoch as well as the comparisons between FTIR and MAX-DOAS columns and model simulations. Concluding remarks and perspectives are included in Sect. 5.

\section{Instrumental setup and data sets}

\subsection{Measurement site}

The high-alpine international scientific station of Jungfraujoch (referred to below as ISSJ, $46.5^{\circ} \mathrm{N}, 8.0^{\circ} \mathrm{E}, 3580 \mathrm{~m}$ a.s.l.; Zander et al., 2008), is located on a mountain saddle between the two summits Jungfrau (4158 m a.s.l.) and Mönch (4099 m a.s.1.) on the northern edge of the Swiss Alps. Due to its particular topographical position representing a strong barrier for synoptic-scale air flow, the ISSJ is mainly influenced by northwesterly winds, advecting air masses to the ISSJ from the Swiss plateau, and southeasterly flows from the inner Alpine region and the south of the Alps (e.g., the Po Valley, Italy). Because of its altitude, the ISSJ is essen- 
tially located in the free troposphere in winter (from November to January) and is influenced by advective weather types (Collaud Coen et al., 2011). During the rest of the year, frequent injections of air masses from the planetary boundary layer (PBL) occur, especially in summer where convective weather types have a greater occurrence (Collaud Coen et al., 2011). Therefore the ISSJ often allows investigation of the atmospheric background conditions over central Europe as well as studying the mixing of PBL and free tropospheric air masses (e.g., Zellweger et al., 2003; Reimann et al., 2004).

As glaciers and barren rocks cover the main area in the closest vicinity of the ISSJ, contamination due to local $\mathrm{HCHO}$ precursor emissions is generally negligible. However, analyses of backward trajectories for background conditions indicated that the air masses at Jungfraujoch have a large contribution of biogenic and anthropogenic emissions from western central Europe, i.e., northern Italy, southern France and southern and eastern Germany (Legreid et al., 2008). They also revealed that the influence of long-range intercontinental transport is discernible, clearly separated from the influence of the European PBL (Henne et al., 2005; Balzani Lööv et al., 2008). Influences from large biogenic and anthropogenic emission sources generally originate from the nearby valleys, such as the Rhône Valley to the south of Jungfraujoch or the Po Valley in northern Italy, and from cities at the foothill of the Alps. These pollutant emissions might be transported to Jungfraujoch by air advection in the upper PBL, thermally driven convection, front passage and efficient tropospheric venting of PBL air masses from deep Alpine valleys, especially during summertime (Lugauer et al., 2000; Henne et al., 2004, 2005; Li et al., 2005). The constituents lifted to the ISSJ are then transported horizontally by the synoptic flow over the Alpine region.

\subsection{FTIR observations and retrieval strategy}

The FTIR data set investigated in this work has been derived from solar spectra recorded under clear-sky conditions at ISSJ with a high spectral resolution commercial Bruker IFS $120 \mathrm{HR}$ spectrometer equipped with indium antimonide and mercury cadmium telluride cooled detectors (we refer to Zander et al., 2008, for further details). It consists of a subset of 1500 spectra (representing 326 days of observations) recorded during the July 2010-December 2012 period with an optical filter covering the $2400-3310 \mathrm{~cm}^{-1}$ spectral domain and maximizing the signal-to-noise $(S / N)$ ratio. This data set has been limited such as to coincide with the observational time of the MAX-DOAS instrument (see following Sect. 2.3). It is characterized by a typical spectral resolution (defined here as the inverse of twice the maximum optical path difference) alternating between 0.003 and $0.005 \mathrm{~cm}^{-1}$ and by $S / N$ ratios ranging from about 550 to 3100 , the highest values being reached for averages of consecutive individual spectra.
All FTIR solar observations have been fitted with the SFIT-2 v3.91 algorithm (Rinsland et al., 1998) based on the optimal estimation formalism of Rodgers (2000). This code performs the derivation of vertical mixing ratio profiles and corresponding column abundances of most of the FTIR target gases and allows the characterization of the vertical information content of the measurement. The model atmosphere above the ISSJ is discretized in a 39-layer scheme of progressively increasing thicknesses (until $100 \mathrm{~km}$ altitude), using physical pressure and temperature information derived on a daily basis from midday pressure-temperature profiles provided by the National Centers for Environmental Prediction (NCEP, http://www.ncep.noaa.gov). Spectroscopic line parameters from the HITRAN 2008 official release (Rothman et al., 2009) are assumed in the spectral fitting process, including the additional line strength updates for $\mathrm{HCHO}$ from Perrin et al. (2009).

The a priori vertical concentration profile for $\mathrm{HCHO}$, as well as for all interfering species in the retrieval process, originates from averaged volume mixing ratio (VMR) profiles derived from WACCM v6 (Whole Atmosphere Community Climate Model; see e.g., Chang et al., 2008) simulations above ISSJ over the 1980-2020 period. This a priori VMR profile for HCHO (see Fig. S1 in the Supplement) presents a good consistency with the zonal average of individual HCHO profiles derived from nearly 2000 occultation observations performed between 36.5 and $56.5^{\circ} \mathrm{N}$ and over the 2004-2012 period by the ACE-FTS instrument version 3.5 (Bernath et al., 2005; Dufour et al., 2009a) within the entire altitude range accessible by ACE-FTS (i.e., from approximately 6 to $40 \mathrm{~km}$ for $\mathrm{HCHO}$ ). The concentration of the simulated $\mathrm{HCHO}$ profiles shows a strong gradient in the troposphere, with maximum values of approximately $0.3 \mathrm{ppbv}$ at the ISSJ altitude $(3580 \mathrm{~m})$, rapidly decreasing to a minimum of $10 \mathrm{pptv}$ in the upper troposphere and the lower stratosphere. These values are in good agreement with in situ observations (e.g., Harder et al., 1997) and airborne measurements (e.g., Fried et al., 2003, 2008; Stickler et al., 2006) carried out in the background continental boundary layer at mid-latitudes in the Northern Hemisphere.

Solar absorption by HCHO in the infrared domain results in very broad spectral features of very weak intensities, especially at ISSJ (generally less than $1 \%$ of the total signal under normal background conditions) because of the station elevation and dominant non-polluted air masses. The FTIR retrieval strategy implemented in this study is based on the method developed by Vigouroux et al. (2009) for the $\mathrm{HCHO}$ retrieval at Reunion Island, who used six microwindows encompassing the $2760-2860 \mathrm{~cm}^{-1}$ spectral domain. The selection of these fitting spectral intervals is discussed in Vigouroux et al. (2009). In the present work, we use four of these microwindows (see Table 1), discarding two due to the presence of systematic residuals or of very strong interferences blinding the weak HCHO absorption. A typical example of FTIR fit for $\mathrm{HCHO}$ at Jungfraujoch is presented in 
Table 1. List of the microwindows used for the FTIR retrieval of $\mathrm{HCHO}$ and the interfering species. The 2765 and $2855 \mathrm{~cm}^{-1} \mathrm{mi}-$ crowindows are used in a first run to pre-fit $\mathrm{HCHO}, \mathrm{HDO}$ and $\mathrm{O}_{3}$ by simple scaling. The scaled profiles of these three compounds are then used as a priori profiles in the retrievals of $\mathrm{HCHO}$.

\begin{tabular}{lc}
\hline Microwindows $\left(\mathrm{cm}^{-1}\right)$ & Interfering species \\
\hline $2763.425-2763.600$ & $\mathrm{HDO}, \mathrm{CH}_{4}, \mathrm{O}_{3}, \mathrm{~N}_{2} \mathrm{O}, \mathrm{CO}_{2}$ \\
$2765.725-2765.975$ & $\mathrm{HDO}, \mathrm{CH}_{4}, \mathrm{O}_{3}, \mathrm{~N}_{2} \mathrm{O}, \mathrm{CO}_{2}$ \\
$2778.200-2778.590$ & $\mathrm{HDO}, \mathrm{CH}_{4}, \mathrm{O}_{3}, \mathrm{~N}_{2} \mathrm{O}, \mathrm{CO}_{2}$ \\
$2855.650-2856.400$ & $\mathrm{HDO}, \mathrm{CH}_{4}, \mathrm{O}_{3}, \mathrm{~N}_{2} \mathrm{O}, \mathrm{H}_{2} \mathrm{O}$ \\
\hline
\end{tabular}

Fig. 1, as well as the simulated HCHO absorption in these four microwindows. The same example of FTIR fit, but using the same six microwindows as Vigouroux et al. (2009), is illustrated in Fig. S2 in the Supplement. The interfering species are $\mathrm{CH}_{4}$ producing the background absorption in every interval, multiple lines of $\mathrm{O}_{3}$ and individual features of $\mathrm{N}_{2} \mathrm{O}, \mathrm{CO}_{2}$, $\mathrm{HDO}$ and $\mathrm{H}_{2} \mathrm{O}$. The 2763 and $2765 \mathrm{~cm}^{-1}$ microwindows are mainly characterized by relatively weak interfering absorptions, the larger $\mathrm{HCHO}$ absorption occurring in the $2778 \mathrm{~cm}^{-1}$ microwindow. The last interval presents small absorptions of $\mathrm{HCHO}$ at approximately $2856.2 \mathrm{~cm}^{-1}$ but encompasses two large features of HDO and solar absorption very helpful in reducing the correlation between HCHO signals and both HDO and solar absorptions in the other microwindows.

Instead of a Tikhonov type L1 regularization as used by Vigouroux et al. (2009) for the HCHO retrieval process, we have opted for an optimal estimation method (OEM; Rodgers, 2000) accounting for the geophysical conditions of the target species. As the covariance matrix should represent the natural variability of $\mathrm{HCHO}$ for each atmospheric layer, we have determined the value of each diagonal element (i.e., a percentage of the a priori profile) by investigating the variability profile of $\mathrm{HCHO}$ on the basis of the solar occultation observations from ACE-FTS v3.5 and simulations of the WACCM model. The averaged relative standard deviations (RSD) of HCHO VMR from ACE-FTS and WACCM present very consistent vertical shapes above ISSJ, indicating a maximum of variability at $10 \mathrm{~km}$ altitude. However, the entire WACCM profile has to be multiplied by a constant factor of approximately 2.5 to approach the values derived from the ACE-FTS observations. Such a difference between the RSD ensembles can be explained by the fact that the model probably underestimates the atmospheric natural variability of $\mathrm{HCHO}$ and that the measurement noise inherent to the ACEFTS observations presumably induces excessive RSD values. However, adoption of a variability profile derived from ACEFTS RSD values was found to lead to strong oscillations in the retrieved tropospheric profiles. Such oscillations are responsible for unphysical negative VMR values of HCHO. Consequently, the diagonal elements of the covariance ma- trix have been adjusted to obtain a compromise between stability and information content. Through several tests we have determined an adequate factor of 1.5 to multiply the RSD profile from WACCM and have adopted these values as diagonal elements of the covariance matrix. The HCHO variability (see Fig. S1) at the ISSJ altitude amounts to $65 \%$, slightly decreases to $55 \%$ at $6 \mathrm{~km}$ altitude and reaches its maximum (approximately $100 \%$ ) at $10-11 \mathrm{~km}$ before rapidly decreasing with the elevation. Given the strong gradient of $\mathrm{HCHO}$ concentration in the troposphere, we have used a Gaussian inter-layer correlation with a half-width length of $3 \mathrm{~km}$ for the off-diagonal elements of the covariance matrix. Finally, a $S / N$ ratio of 600 for inversion is set in all fitting sequences, consistent with the noise level of most of the analyzed solar spectra.

In the present study, the fitting process of an individual FTIR solar spectrum to retrieve HCHO at ISSJ consists of two successive steps. In the first one, which is a pre-fitting step, the a priori VMR profiles of $\mathrm{HCHO}, \mathrm{HDO}$ and $\mathrm{O}_{3}$ provided by the WACCM model are independently scaled in the $2765.725-2765.975$ and $2855.650-2856.400 \mathrm{~cm}^{-1} \mathrm{mi}-$ crowindows only (without taking into account the other interfering compounds in these microwindows), using a single parameter for each scaled species. These spectrum-specific scaled profiles are then used as a priori for HCHO, HDO and $\mathrm{O}_{3}$ in the $\mathrm{HCHO}$ retrieval process by the OEM (i.e., the second step) involving the four microwindows and all the interfering species listed in Table 1. During this second step, the vertical distribution of each interfering species is independently varied over their entire altitude spans. The pre-fit (i.e., scaling) of the $\mathrm{HCHO}$ a priori in the first step helps to avoid strong oscillations during the retrieval process by the OEM in the second step and the related unphysical profiles that may be produced.

\subsection{MAX-DOAS observations and retrieval strategy}

The ground-based passive MAX-DOAS technique has already been applied to the HCHO detection (e.g., Heckel et al., 2005; Irie et al., 2011; Wagner et al., 2011; Pinardi et al., 2013), revealing a good consistency with HCHO observations from SCIAMACHY nadir viewing satellite (Wittrock et al., 2006), LP (long-path) DOAS instrument (Pikelnaya et al., 2007), PTR-MS (proton transfer reaction mass spectrometry) data (Inomata et al., 2008) and during the airborne INTEX-B (INtercontinental chemical Transport Experiment) campaign (Fried et al., 2011).

A MAX-DOAS spectrometer designed and assembled at the Belgian Institute for Space Aeronomy has been operating at ISSJ since July 2010. A detailed explanation of the instrument is provided in Clémer et al. (2010), Hendrick et al. (2014) and Wang et al. (2014). In brief, it is a dual-channel system composed of two grating spectrometers covering the UV (300-390 nm) and visible $(400-580 \mathrm{~nm}$ here instead of $400-720 \mathrm{~nm}$ for our instrument operating in China; see the 

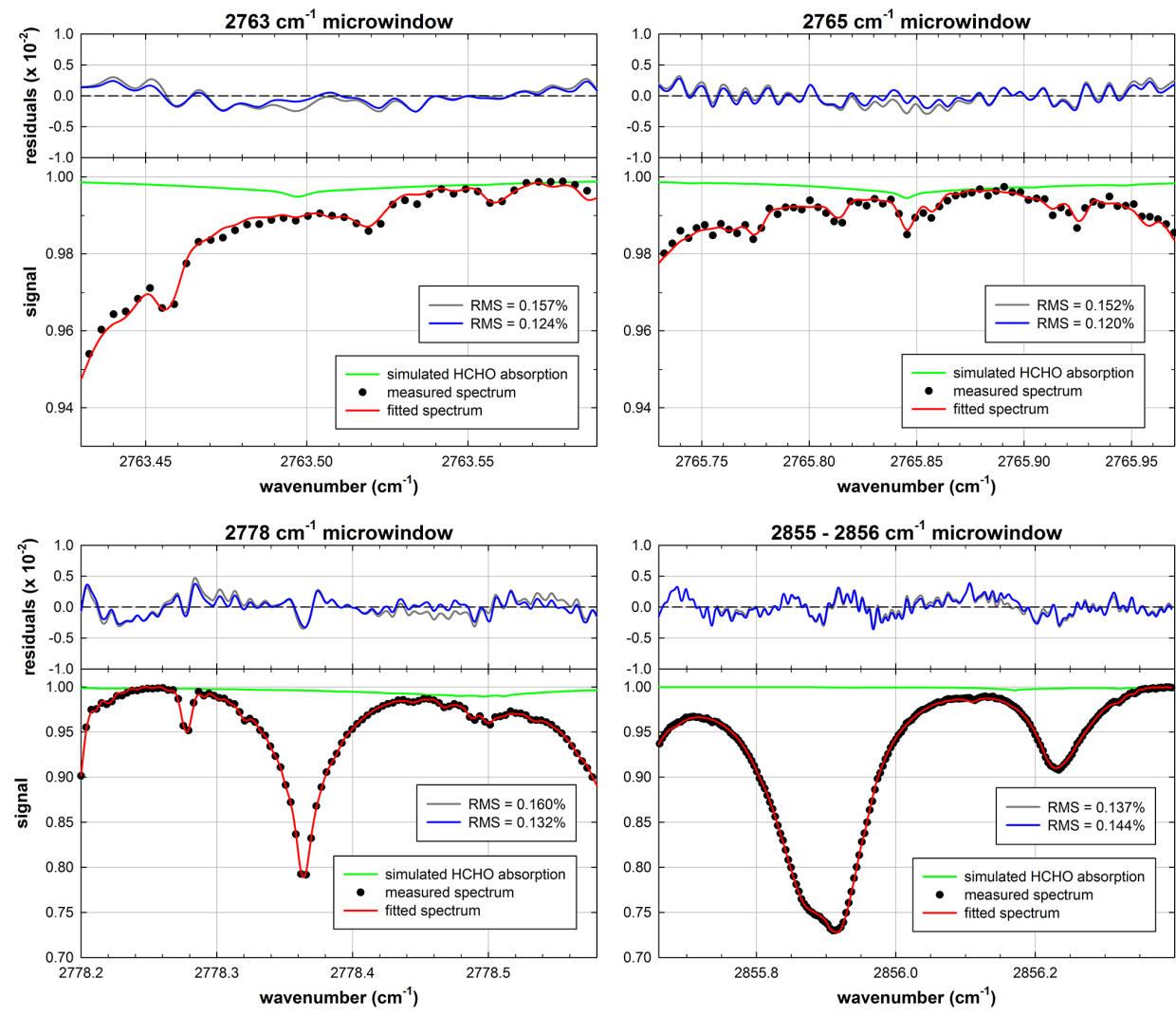

Figure 1. Typical example of HCHO FTIR spectral fits at ISSJ: 22 August 2010, 06:40 UTC, with a SZA of 80 . The related residuals when fitting $\mathrm{HCHO}$ absorption and assuming no $\mathrm{HCHO}$ absorption are in blue and grey curves, respectively. This solar spectrum is characterized by a $S / N$ ratio of 1656 and produced a DOFS equal to 1.02 and $\mathrm{HCHO}$ total column of $1.26 \times 10^{15} \mathrm{molec}^{-2}$ (compared to a $S / N$ ratio of 1627, a DOFS of 1.05 and HCHO total column of $1.56 \times 10^{15}$ molec cm ${ }^{-2}$ averaged over the whole FTIR July 2010-December 2012 data set). The solid green line corresponds the HCHO solar absorption simulated at the ISSJ for the same date and SZA. Note that this FTIR fit corresponds to the same date as the DOAS fit example in Fig. 2. This figure can be compared to Fig. S2, representing the same HCHO FTIR spectral fits but using the six microwindows from Vigouroux et al. (2009).

three references here above) wavelength ranges and connected to cooled CCD detectors. The instrumental function is close to a Gaussian with a full width at half maximum of 0.4 and $0.5 \mathrm{~nm}$ in the UV and visible, respectively. The optical head is mounted on a commercial sun tracker (INTRA, Brusag) and is linked to the spectrometers through optical fibers. The instrument is pointing towards the city of Bern (northwest direction) and a full MAX-DOAS scan consists of the following elevation angles: $-10,-8,-6,-4,-2,0$, $1,3,4,5,8,10,15,30$ and $90^{\circ}$ (zenith). The negative elevations, i.e., when the instrument points downwards the valley, as well as azimuthal scans performed around local noon were not used in the present study.

The data set investigated here covers the July 2010December 2012 time period. The retrieval of HCHO vertical profiles and corresponding column amounts is performed in two steps: (1) DOAS spectral fitting providing the so-called differential slant column densities (DSCDs) and (2) application of an OEM-based profiling method on the HCHO
DSCDs to retrieve vertical profiles. These two steps are described below.

\subsubsection{DOAS analysis}

Measured scattered-sunlight spectra are analyzed using the QDOAS spectral fitting software suite (http://uv-vis. aeronomie.be/software/QDOAS/). The principle of the DOAS technique is to separate high-frequency molecular absorption features from a broadband component accounting for scattering and instrumental effects (Platt and Stutz, 2008). The DOAS spectral fitting yields DSCDs, which are expressed in molec $\mathrm{cm}^{-2}$ and correspond to the concentration of a given absorber integrated along the effective light path relative to the amount of the same absorber in a measured reference spectrum. In the case of MAX-DOAS, the zenith spectrum of each scan is often taken as reference in order to remove the stratospheric contribution in off-axis measurements (Hönniger et al., 2004). 


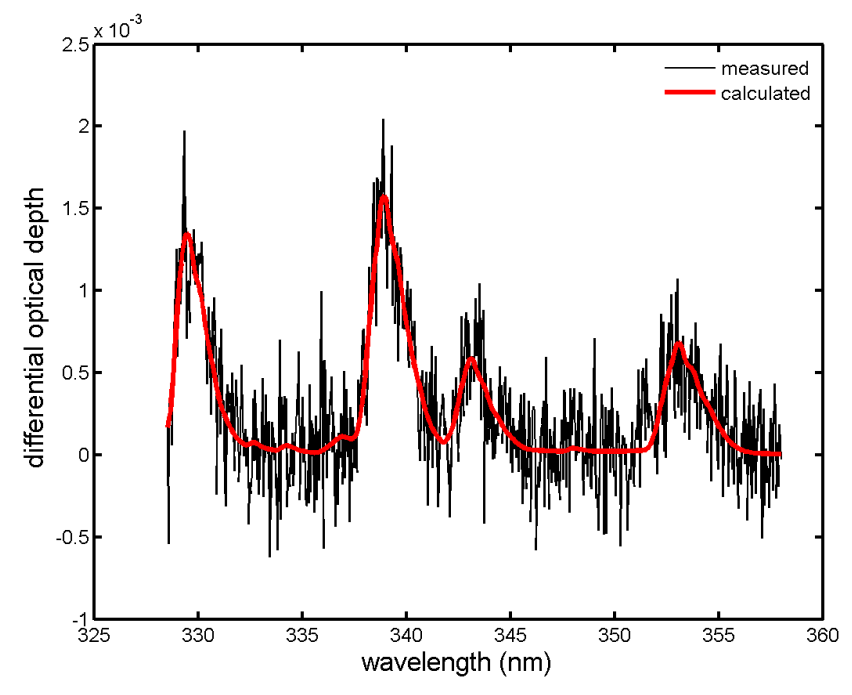

Figure 2. Example of HCHO DOAS fit at ISSJ. It corresponds to 22 August 2010 (the same date as the FTIR fit example presented in Fig. 1) at 16:30 UTC and $0^{\circ}$ elevation.

HCHO DSCDs are retrieved in the $328.5-358.0 \mathrm{~nm}$ wavelength range. Compared to previously published $\mathrm{HCHO}$ DOAS settings (Vigouroux et al., 2009; Pinardi et al., 2013), the fitting interval is extended here towards the UV for minimizing the $\mathrm{HCHO} / \mathrm{BrO}$ correlation. The zenith spectrum of each scan is used as reference, leading to a reduction of the interference by $\mathrm{O}_{3}$ and of the impact of possible instrumental degradation. ISSJ, being a remote station, has low $\mathrm{HCHO}$ content and as a result these two settings are found to significantly improve the DOAS fit. The following spectral signatures are taken into account: $\mathrm{HCHO}$ at $293 \mathrm{~K}$ (Meller and Moortgat, 2000), $\mathrm{NO}_{2}$ at $298 \mathrm{~K}$ (Vandaele et al., 1998), $\mathrm{O}_{3}$ at $223 \mathrm{~K}$ and $243 \mathrm{~K}$ (Bogumil et al., 2003) plus additional correction terms according to Puķite et al. (2010), $\mathrm{O}_{4}$ (Thalman and Volkamer, 2013), BrO at $223 \mathrm{~K}$ (Fleischmann et al., 2004) and the Ring effect (Grainger and Ring, 1962; Chance and Spurr, 1997). A fifth-order polynomial is included to fit the broadband structure (Pinardi et al., 2013) and a linear correction for the intensity off-set is used. A typical example of a DOAS fit for HCHO at ISSJ is shown in Fig. 2 (for the same date as the FTIR fit example in Fig. 1).

\subsubsection{Profile retrieval}

HCHO vertical profiles are retrieved by applying the OEMbased profiling tool bePRO to the HCHO DSCDs. Since bePRO is already described in several papers (Clémer et al., 2010; Hendrick et al., 2014; Wang et al., 2014), only the main features are given here. This application uses a two-step approach for trace gas profile retrieval. First, aerosol extinction profiles are retrieved for each scan from measured $\mathrm{O}_{4}$ DSCDs (Frieß et al., 2006; Clémer et al., 2010). This step is needed since aerosols significantly affect the effective light path through the atmosphere (Wagner et al., 2004) and therefore the optical density of trace gases. Secondly, HCHO vertical profiles are inverted from the measured HCHO DSCDs using the aerosol extinction profiles obtained in the first step as input for the calculation of the so-called weighting functions $\mathbf{K}$ which describe the relation between the measured DSCDs and vertical profiles. These are calculated using the LIDORT radiative transfer model (Spurr et al., 2008) as the forward model.

Other key parameters in the OEM are the a priori profile $\boldsymbol{x}_{\mathrm{a}}$, its covariance matrix $\mathbf{S}_{\mathrm{a}}$ and the measurement uncertainty covariance matrix $\mathbf{S}_{\varepsilon}$. For $\mathrm{HCHO}$, the same a priori vertical profile as for FTIR is used, i.e., the HCHO profile derived from WACCM model simulations over the 1980 2020 time period above ISSJ. In the case of the a priori for aerosol retrieval, an extinction profile corresponding to rural conditions with a visibility of $70 \mathrm{~km}$ is selected from the LOWTRAN climatology (Shettle, 1989). Due to the absence of AERONET data at ISSJ, aerosol single scattering albedo and phase function at $340 \mathrm{~nm}$ are estimated off-line based on a first approximation on the aerosol size distribution and refractive index retrieved from AERONET data at Observatoire de Haute-Provence ( $44^{\circ} \mathrm{N}, 5.5^{\circ} \mathrm{E}, 600 \mathrm{~m}$ a.s.l.) station. $\mathbf{S}_{\varepsilon}$ and $\mathbf{S}_{\mathrm{a}}$ matrices for both aerosols and HCHO are constructed as in Clémer et al. (2010; see also Hendrick et al., 2014; Wang et al., 2014). For $\mathbf{S}_{\mathrm{a}}$, the diagonal element corresponding to the lowest layer, $\mathbf{S}_{\mathbf{a}}(1,1)$, is set equal to the square of a scaling factor $\beta$ times the maximum partial aerosol optical depth or vertical column density (VCD) of the profiles. Here $\beta=0.6$ for $\mathrm{HCHO}$ and 0.4 for aerosol. The other diagonal elements decrease linearly with altitude down to $0.2 \times \mathbf{S}_{\mathrm{a}}(1,1)$. The off-diagonal terms in $\mathbf{S}_{\mathrm{a}}$ are set using Gaussian functions with a correlation length of $0.2 \mathrm{~km}$ for both $\mathrm{HCHO}$ and aerosol retrievals. $\mathbf{S}_{\varepsilon}$ is a diagonal matrix, with variances equal to the square of the DOAS fitting error. US Standard Atmosphere pressure and temperature profiles and a surface albedo of 0.2 are used and the following altitude grid is selected: 10 layers of $200 \mathrm{~m}$ thickness between 3.6 and $6 \mathrm{~km}$ and one layer of $2 \mathrm{~km}$ between 6 and $8 \mathrm{~km}$.

Each retrieval is quality-checked based on the DOFS (degree of freedom for signal, which corresponds to trace of the averaging kernel matrix A; see also Sect. 3.1) and the relative root mean square error (RMS) between measured and calculated DSCDs. This RMS corresponds to the standard RMS expressed in molec $\mathrm{cm}^{-2}$ divided by the mean DSCD of the scan. The following criteria have been chosen for the selection of good scans: DOFS $>1$, RMS $<30 \%$ and no negative concentration/extinction coefficient values allowed. Since HCHO and aerosol contents are particularly low at ISSJ, their retrieval can be strongly affected by the presence of clouds. The cloud screening method developed by Gielen et al. (2014) and based on the measured color index (CI) at zenith has been therefore utilized as an additional selection criterion. This empirical parameter gives information about the color of the sky: from blue during clear skies 
to white/grey when clouds or aerosols are present. Based on the comparison between measured and simulated CI, the following sky conditions can be defined for each MAX-DOAS scan: clear-sky, thin (white/light grey) clouds/polluted, thick (dark grey) clouds/heavily polluted and broken clouds. In the present study, MAX-DOAS scans corresponding to thick clouds or broken clouds are rejected since the quality of the aerosol and trace gas retrievals can be potentially strongly affected by these sky conditions.

\subsection{GEOS-Chem simulations}

The global GEOS-Chem CTM (version 9-01-03: http://acmg.seas.harvard.edu/geos/doc/archive/man.

v9-01-03/index.html) is driven by NASA Global Modeling Assimilation Office GEOS-5 assimilated meteorological fields. The GEOS-5 data are at a native horizontal resolution of $0.5 \times 0.667^{\circ}$ with 72 vertical levels at $6 \mathrm{~h}$ temporal frequency ( $3 \mathrm{~h}$ for surface variables and mixing depths). We use the GEOS-5 data at $2 \times 2.5^{\circ}$ and 47 vertical levels, combining levels above $\sim 80 \mathrm{hPa}$. GEOS-Chem includes detailed $\mathrm{O}_{3}-\mathrm{NO}_{x}-\mathrm{VOC}$-aerosol coupled chemistry originally described by Bey et al. (2001) and Park et al. (2004) with updates by Mao et al. (2010). The model simulates the distributions of 95 species and chemistry of 22 precursor non-methane VOCs (NMVOCs). The isoprene oxidation mechanism is described in Mao et al. (2013).

Global biogenic emissions are obtained with the Model of Emissions of Gases and Aerosols from Nature (MEGAN) v2.0 (Guenther et al., 2006) and biomass burning emissions are from the Global Fire Emission Database (GFED) v3 (van der Werf et al., 2010). Over Europe, anthropogenic emissions of $\mathrm{CO}, \mathrm{NO}_{x}, \mathrm{SO}_{x}$ and $\mathrm{NH}_{3}$ are provided by the $\mathrm{Eu}-$ ropean Monitoring and Evaluation Programme (EMEP; http: //www.ceip.at/) regional inventory (Simpson et al., 2010) for the year 2010. GEOS-Chem uses the RETRO emission inventory (Schultz et al., 2007) for base year 2000 for all anthropogenic NMVOC emissions other than methyl ethyl ketone, acetaldehyde, propene and $>=\mathrm{C}_{4}$ alkanes, which are provided by the EMEP inventory. These anthropogenic emissions are scaled to the years of interest using energy statistics (van Donkelaar et al., 2008). An offline simulation is used for anthropogenic ethane emissions (Xiao et al., 2008). Annual average $\mathrm{CH}_{4}$ concentrations prescribed over four latitude bands $\left(0-30^{\circ} ; 30-90^{\circ}\right)$ are informed by $\mathrm{CH}_{4}$ measurements from the NOAA Global Monitoring Division flask measurements.

We use GEOS-Chem results for the common observation period (July 2010-December 2012) after 1 year of spin-up for chemical initialization. The GEOS-Chem data set used in the present work consists of HCHO VMR profiles simulated at the closest pixel to the ISSJ and saved at a $3 \mathrm{~h}$ time step.

\subsection{IMAGES simulations}

IMAGES v2 is a global CTM simulating the distributions of 132 trace compounds at a resolution of $2 \times 2.5^{\circ}$ and at 40 hybrid pressure-sigma levels between the Earth's surface and the lower stratosphere (Stavrakou et al., 2009a, b, 2013). The model includes the chemistry of 22 precursor NMVOCs. The isoprene oxidation mechanism follows the LIM0 scheme (Peeters and Müller, 2010) with revised reaction rates from the updated theoretical estimation of Peeters et al. (2014). Accounting for the isomerization of isoprene peroxy radicals reduces the yields of $\mathrm{HCHO}$ by about $10 \%$ in most atmospheric conditions (Stavrakou et al., 2014).

Meteorological fields are obtained from ERA-Interim analyses of the European Center Medium-Range Weather Forecasts (ECMWF). The parameterizations for deep convection and turbulent mixing in the boundary layer use the ERA-Interim updraft mass fluxes and turbulent diffusion coefficients for heat. The model time step is taken equal to $4 \mathrm{~h}$. As described in more detail in Stavrakou et al. (2009b), the effects of diurnal variations are accounted for through correction factors calculated from a detailed model run with a 20 min time step. This diurnal cycle simulation accounts for diurnal variation in the photolysis rates, meteorological parameters and emissions.

The model uses anthropogenic emissions of $\mathrm{CO}, \mathrm{NO}_{x}$, $\mathrm{SO}_{x}$ and $\mathrm{NH}_{3}$ over Europe from EMEP for the year 2010 and anthropogenic emissions of NMVOCs from the RETRO inventory for the year 2000 (Schultz et al., 2007). It is worth noting that RETRO NMVOC emissions appear to be largely overestimated compared to EMEP estimates: for example, total emissions between 40 and $60^{\circ} \mathrm{N}$ and between $10^{\circ} \mathrm{W}$ and $60^{\circ} \mathrm{E}$ are $25.7 \mathrm{Tg}$ in RETRO and only $10.3 \mathrm{Tg}$ in EMEP for 2011. The seasonal variation of anthropogenic emissions is estimated as in Stavrakou et al. (2013). Diurnal and weekly profiles of $\mathrm{CO}, \mathrm{NO}_{x}$ and VOC anthropogenic emissions for OECD countries are obtained from Jenkin et al. (2000). Biomass burning emissions are provided by GFED v3 (van der Werf et al., 2010). Isoprene biogenic emissions are obtained from the MEGAN-MOHYCAN inventory (Stavrakou et al., 2014), whereas methanol biogenic emissions are obtained from an inversion of emissions based on IASI (Infrared Atmospheric Sounding Interferometer) satellite data (Stavrakou et al., 2011). The calculation of inorganic species and aerosols is described in Stavrakou et al. (2013). Monthly latitude-dependent $\mathrm{CH}_{4}$ concentration profiles constructed from NOAA Global Monitoring Division measurements are used to specify both the initial conditions and the surface boundary conditions for this compound in the model.

The IMAGES data set used in the present work consists of HCHO VMR profiles simulated at the closest pixel to the station and saved at a $4 \mathrm{~h}$ time step. 

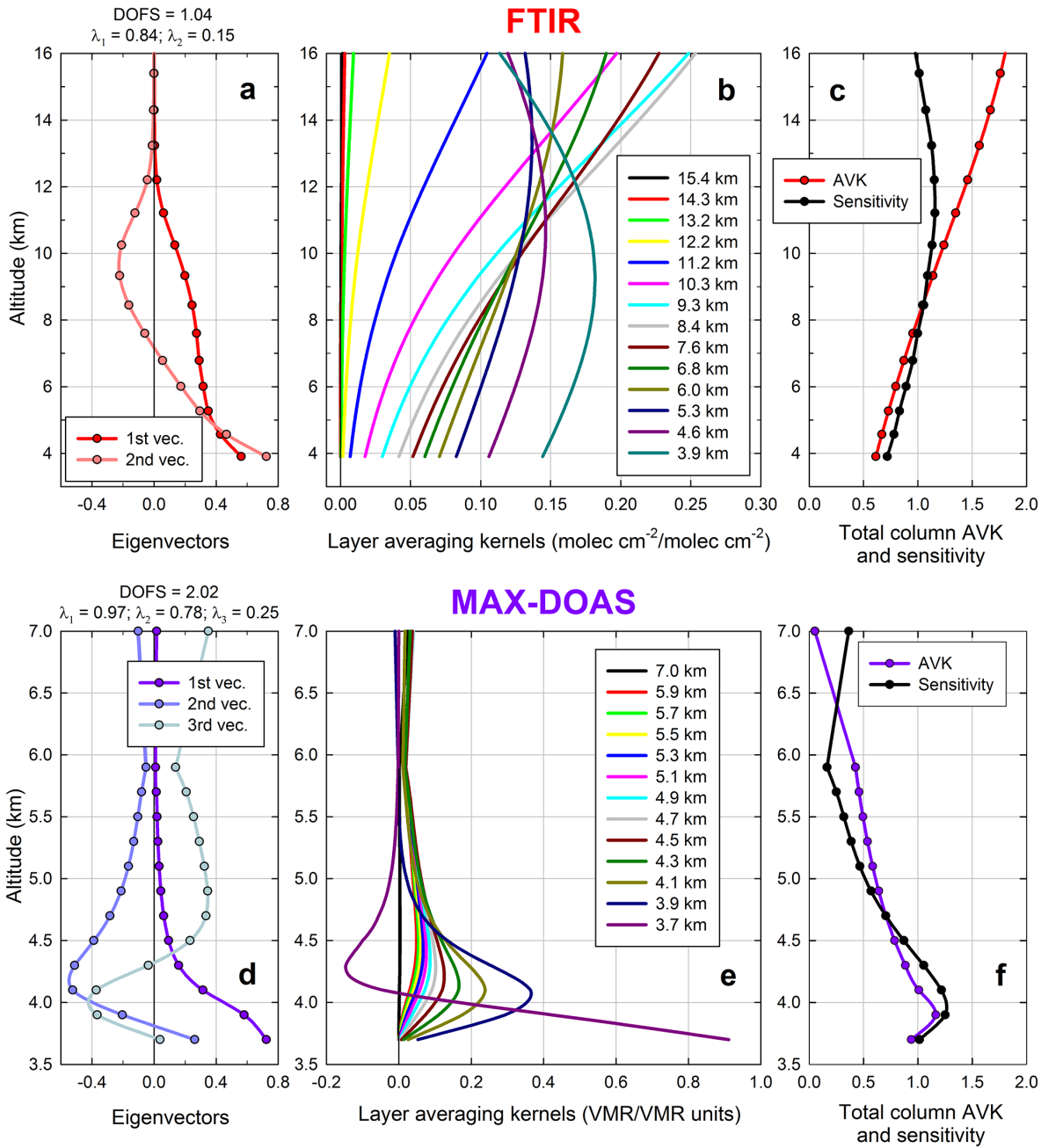

Figure 3. First eigenvectors and the associated eigenvalues (a and d), layer averaging kernels (b and e) and total column averaging kernel $(\mathrm{AVK})$ and sensitivity profile (c and $\mathbf{f}$ ) characterizing the FTIR (upper frames) and MAX-DOAS (lower frames) retrievals of HCHO above Jungfraujoch. Note that the layer averaging kernels are expressed in molec $\mathrm{cm}^{-2}\left(\operatorname{molec~} \mathrm{cm}^{-2}\right)^{-1}$ for FTIR and in VMR/VMR units for MAX-DOAS. These information parameters have been calculated on the basis of all the individual profiles retrieved over the July 2010December 2012 time period.

\section{Characterization of remote sensing data and error budgets}

\subsection{Characterization of the FTIR and MAX-DOAS retrievals}

In the ill-posed inversion problem determining the retrieved vertical distribution $\boldsymbol{x}_{\mathrm{r}}$ of a target absorber along the vertical $(z)$ in the atmosphere, $\boldsymbol{x}_{\mathrm{a}}$ and $\boldsymbol{x}_{\mathrm{t}}$ are the a priori and true vertical profiles of the target absorber, respectively, and $\mathbf{A}$ is the averaging kernel matrix (i.e., the product of the retrieval process) describing how the retrieved profile is related to $\boldsymbol{x}_{\mathrm{a}}$ and $\boldsymbol{x}_{\mathrm{t}}$ according to Eq. (1) and characterizing the information content of the retrievals.

$\boldsymbol{x}_{\mathrm{r}}(z)=\boldsymbol{x}_{\mathrm{a}}+\mathbf{A}\left(\boldsymbol{x}_{\mathrm{t}}-\boldsymbol{x}_{\mathrm{a}}\right)$
The typical layer averaging kernels in the troposphere, corresponding to the mean averaging kernels calculated on the basis of the 2010-2012 individual profiles and obtained from the FTIR and MAX-DOAS HCHO retrievals, are drawn in Fig. 3. They are expressed in molec $\mathrm{cm}^{-2}\left(\text { molec } \mathrm{cm}^{-2}\right)^{-1}$ for FTIR (Fig. 3b) and in VMR/VMR units for MAX-DOAS (Fig. 3e). Corresponding eigenvectors and leading eigenvalues are represented in Fig. 3a and d for FTIR and MAXDOAS, respectively.

Regarding FTIR, the mean DOFS is 1.04 with a $1 \sigma$ standard deviation (SD) of 0.3 (including all measurements at different SZA). The DOFS value and the eigenvectors indicate that the FTIR averaging kernels are not vertically resolved and that the retrieved profiles are sensitive only to a change in the true profile $\boldsymbol{x}_{\mathrm{t}}$ between the ISSJ elevation and $12 \mathrm{~km}$ altitude. Within this altitude range, the total col- 
umn averaging kernel and the sensitivity profile (see Fig. 3c), indicating the fraction of the retrievals originating from the measurements rather than from the a priori information $\left(\boldsymbol{x}_{\mathrm{a}}\right)$, show values relatively close to 1.0 , meaning that most of the information is coming from the measurements. The total column averaging kernel and the corresponding sensitivity profile displayed in Fig. $3 \mathrm{c}$ are consistent with those shown in Viatte et al. (2014). On average over all the individual FTIR retrieved profiles, the $\mathrm{HCHO}$ column below $12 \mathrm{~km}$ altitude represents $95.4 \%$ of the total column.

In contrast to FTIR, two independent pieces of information in the troposphere (mean DOFS $=2.02$ ) may be obtained from the MAX-DOAS measurements. According to the eigenvector decomposition (Fig. 3d), the averaging kernels (Fig. 3e) and the column averaging kernel and sensitivity (Fig. 3f), most of the information on the vertical distribution of HCHO contained in the measurements is located below $5.5 \mathrm{~km}$ altitude, with a maximum sensitivity in the lowest layers close to the ground. The first eigenvector is found to be mainly responsible for the strong sensitivity in the lowermost layer, with $97 \%$ of the information content independent from the a priori profile $\left(\boldsymbol{x}_{\mathrm{a}}\right)$. The following eigenvectors mainly contribute to increasing the sensitivity of the retrievals at upper levels in the troposphere. Nevertheless, the contribution of the MAX-DOAS retrievals to the information content is rapidly decreasing with the elevation (e.g., this contribution is reduced to $50 \%$ approximately at $5 \mathrm{~km}$ altitude). These results show that the concentration in the lowest layer (3.6$3.8 \mathrm{~km}$ ) in addition to the $3.6-8 \mathrm{~km}$ partial column can be retrieved from the MAX-DOAS observations at ISSJ. However, the discussion will be mainly focused on the $3.6-8 \mathrm{~km}$ partial columns in the present study.

It can be concluded that the FTIR and MAX-DOAS retrievals have a different vertical resolution and sensitivity to the vertical distribution of $\mathrm{HCHO}$, with the former being vertically unresolved and mainly sensitive in the free troposphere up to the tropopause and the latter characterizing the $\mathrm{HCHO}$ abundance in the lower vertical layers in the vicinity of the ISSJ. Therefore, direct comparisons of retrieved HCHO abundances from both techniques have little meaning, but ground-based FTIR and MAX-DOAS observations provide complementary information on the $\mathrm{HCHO}$ distribution in the atmosphere, more specifically in the lowermost troposphere (see Fig. S3). Nevertheless, we will use simulated HCHO distributions of two three-dimensional CTMs (GEOS-Chem and IMAGES) as intermediates to investigate the consistency between the retrieved HCHO columns (e.g., the seasonal cycle) above Jungfraujoch, taking into account the specific vertical resolution and sensitivity of both remote sensing techniques by applying their respective averaging kernels to smooth the CTM profiles of $\mathrm{HCHO}$ (Rodgers and Connor, 2003).

\subsection{FTIR error budget}

We present in Table 2 an error budget accounting for the major uncertainties that may affect the $\mathrm{HCHO}$ columns retrieved from individual FTIR solar spectra above the ISSJ. This error budget has been split into a systematic and a random component (14.2 and $21.3 \%$, respectively), with an assumed variability (i.e., diagonal of covariance) close to $50 \%$. For both components, the total uncertainty is the square root of the sum of the squares of the estimated contributions from the different error sources listed in Table 2. While most of the error terms have been dealt with using perturbation methods applied to all solar spectra recorded during the year 2011 (details are given in third column of Table 2), the contributions of measurements noise $(14.7 \%)$, smoothing $(10.2 \%)$ and forward model parameters $(2.1 \%)$ to the random component have been computed following the OEM formalism of Rodgers (2000), i.e., by calculating the gain and sensitivity matrices, on the basis of a representative subset of solar spectra.

The largest contribution to the total systematic error results from the spectroscopic uncertainties in line intensities $(9.7 \%)$ and air-broadening coefficients $(8.0 \%)$ for $\mathrm{HCHO}$. We have accounted for an error of $10 \%$ in the HCHO spectroscopic line strengths, commensurate with the work of Perrin et al. (2009) who reported uncertainties between 7 and $10 \%$ for the HCHO features used in this study. The airbroadened half-width in the HITRAN 2008 database, unchanged since the first HITRAN releases (Rothman, 1981), is derived from the early work of Tejwani and Yeung (1977) and is equivalent to the $10 \%$ uncertainty assumed here. The same error value was used by both Jones et al. (2009) and Vigouroux et al. (2009). Other contributions to the systematic component originate from the spectroscopy of the interfering species $(5.2 \%)$, calculated independently for each gas by applying the maximal uncertainties stated in the HITRAN 2008 compilation on the line intensities during the retrieval process.

In the present study, we have adopted the HITRAN 2008 database for all FTIR retrievals. We have also tested over the 2010-2012 time period the spectroscopic line parameters and air-broadening coefficients from the recent HITRAN 2012 database (Rothman et al., 2013), providing updated self- and $\mathrm{N}_{2}$-broadening coefficients of $\mathrm{HCHO}$, as well as their temperature dependence, on the basis of the work of Jacquemart et al. (2010). With respect to our HITRAN 2008 setup, the use of the full HITRAN 2012 compilation considerably decreases the HCHO retrieved columns by $49.0 \pm 24.6 \%$ over the 2010-2012 time period and induces the rejection of $21.2 \%$ of all spectra due to negative VMR profiles (instead of $8.9 \%$ initially). We have then gauged the impact of the HITRAN 2012 parameters for the main interfering species separately, adopting still HITRAN 2008 for all other absorbers. Compared to our initial setup (full HITRAN 2008), the use of the sole $\mathrm{HCHO}$ parameters have a limited impact on the 
Table 2. Impact of major sources of systematic and random uncertainties on typical individual HCHO total column retrievals from FTIR solar spectra above the Jungfraujoch station. These uncertainties have been calculated on the basis of all individual solar spectra recorded during the year 2011 with the exception of the measurement noise, smoothing and model parameter contributions that have been estimated according to the OEM formalism of Rodgers (2000) on the basis of a representative subset of solar spectra.

\begin{tabular}{lrl}
\hline Error source & Error $(\%)$ & Comments \\
\hline Assumed variability & 49.7 & WACCM variability relaxed, commensurate with ACE-FTS variability down to 6 km \\
\hline Systematic errors & & \\
\hline Line intensity HCHO & 9.7 & Assuming $\pm 10 \%$ uncertainties in HCHO line strengths \\
Air-broadening coefficient HCHO & 8.0 & Assuming $\pm 10 \%$ uncertainties in HCHO air-broadening coefficients \\
Line intensity interfering gases & 5.2 & Assuming the maximal HITRAN 2008 uncertainties \\
Instrumental line shape & 2.5 & $\pm 10 \%$ misalignment and instruments bias \\
Forward model & 1.0 & Retrieval algorithm-related \\
HCHO a priori profile & 3.0 & Assuming HCHO a priori profiles derived from ACE-FTS, GEOS-Chem and IMAGES \\
\hline Total systematic error & 14.2 & \\
\hline Random errors & & \\
\hline Temperature profile & 5.0 & Assuming the NCEP profile uncertainty pattern (see text) \\
H 2 and HDO a priori profiles & 10.1 & Changes by a factor of 2 in a priori slope \\
SZA & 0.7 & Assuming $\pm 0.1^{\circ}$ bias \\
Measurement noise & 14.7 & \\
Smoothing & 10.2 & \\
Model parameters & 2.1 & \\
\hline Total random error & 21.3 & \\
\hline
\end{tabular}

Table 3. Error budget on the retrieved HCHO vertical column density (VCD) for the MAX-DOAS measurements. The total uncertainty is calculated by adding the different error terms in Gaussian quadrature.

\begin{tabular}{lc}
\hline Error sources & $\begin{array}{c}\text { Uncertainty on } \\
\text { HCHO VCD }(\%)\end{array}$ \\
\hline Smoothing and noise errors & 9.1 \\
Uncertainty related to aerosols & 6.3 \\
Uncertainty related to the a priori & 8.8 \\
Uncertainty related to the albedo & 1.0 \\
Uncertainty on the HCHO cross sections & 9.0 \\
\hline Total uncertainty & 16.8 \\
\hline
\end{tabular}

retrieved columns $(-9.3 \pm 5.6 \%)$, while the use of HITRAN 2012 for $\mathrm{CH}_{4}$ only induces a bias of $-11.2 \pm 5.0 \%$ on the HCHO amounts. Finally, when assuming HITRAN 2012 for $\mathrm{CO}_{2}$, the line positions and intensities of which have been modified compared to HITRAN 2008, the retrieved HCHO columns are affected by $-26.9 \pm 15.6 \%$. Although $\mathrm{CO}_{2}$ is not the main interfering species in our microwindows, $\mathrm{CO}_{2}$ lines overlap the $\mathrm{HCHO}$ features in the 2765 and $2778 \mathrm{~cm}^{-1}$ microwindows and largely influence the HCHO absorption. When assumed together, the updated parameters for $\mathrm{HCHO}$, $\mathrm{CH}_{4}$ and $\mathrm{CO}_{2}$ have a cumulative effect and significantly decrease the retrieved $\mathrm{HCHO}$ columns.
For estimating the impact of a bias in the instrumental line shape, we have considered a misalignment of $10 \%$ at the maximal path difference of the instrument, inducing a discrepancy of $2.5 \%$ on the mean HCHO total column. According to comparisons between the SFIT and PROFFIT fitting algorithms, an algorithm-related error of maximum $1 \%$ on the retrieved columns may arise (Hase et al., 2004). Finally, we have fitted the 2011 solar spectra by assuming successively $\mathrm{HCHO}$ a priori profiles derived from the ACE-FTS, GEOS-Chem and IMAGES data sets used in the present work, resulting in retrieved $\mathrm{HCHO}$ amounts diverging by up to $3.0 \%$.

Among the random errors, we adopted the uncertainties provided by NCEP for the temperature (i.e., $1.5^{\circ} \mathrm{C}$ up to $20 \mathrm{~km}, 2^{\circ} \mathrm{C}$ up to $30 \mathrm{~km}, 5^{\circ} \mathrm{C}$ near $35 \mathrm{~km}$ and then progressively increasing up to $9^{\circ} \mathrm{C}$ at $50 \mathrm{~km}$ ), and we further assumed a $0.1^{\circ}$ error in the solar pointing. Although HDO is accounted for during the first run in the retrieval process, there is a relatively strong dependence of the retrieved $\mathrm{HCHO}$ columns on the $\mathrm{H}_{2} \mathrm{O}$ and $\mathrm{HDO}$ a priori profiles (10.1\%). This uncertainty has been estimated by making the slope of the tropospheric $\mathrm{H}_{2} \mathrm{O}$ and HDO VMR profiles simulated by WACCM vary by a factor of 2 . This latter corresponds approximately to the change of slope when taking the $2 \sigma \mathrm{SD}$ limits around the annually-averaged $\mathrm{H}_{2} \mathrm{O}$ VMR profile retrieved above the ISSJ according to the method of Sussmann et al. (2009). 


\subsection{MAX-DOAS error budget}

The error budget on the retrieved MAX-DOAS HCHO VCDs is estimated as in Hendrick et al. (2014) and Wang et al. (2014). The following error sources are taken into account: smoothing and measurement noise errors, uncertainties on the forward model parameters (mainly aerosol extinction, $\mathrm{HCHO}$ a priori profiles and albedo) and uncertainty on the $\mathrm{HCHO}$ cross sections. The error budget is summarized in Table 3. The combined smoothing and measurement noise errors reach $9.1 \%$. Regarding the uncertainty related to the aerosol profile retrieval, an error of $6.3 \%$ is obtained on average on the retrieved HCHO VCD based on a sensitivity test approach using aerosol extinction profiles plus their corresponding error (i.e., the sum of smoothing and noise errors plus a $20 \%$ error due to the uncertainty in the $\mathrm{O}_{4}$ cross sections; see Wagner et al., 2009 and Clémer et al., 2010) as input and comparing the results to the standard $\mathrm{HCHO}$ retrievals. The impact of the a priori $(8.8 \%)$ is estimated by taking the mean HCHO profile derived from the IMAGES model output above ISSJ instead of the WACCM model output. In the case of the surface albedo, a value of 0.2 is used throughout the year while the Koelemeijer et al. (2003) climatology shows it can vary from 0.2 (winter) to 0.05 (summer) above the ISSJ area. The related impact on the HCHO VCD is small (1\%). The uncertainty of $9 \%$ on the $\mathrm{HCHO}$ cross sections is taken from Pinardi et al. (2013).

\section{Results}

In this section, we present the daily-averaged $\mathrm{HCHO}$ products retrieved from the ground-based FTIR and MAX-DOAS observations recorded at ISSJ and their comparison to both GEOS-Chem and IMAGES models, taking into account the vertical resolution and specific sensitivity of each remote sensing technique. The individual concentration profiles of HCHO simulated by both CTMs throughout the July 2010December 2012 time period have been interpolated onto the respective vertical grids of FTIR and MAX-DOAS (see Sect. 3.1), then daily averaged and finally smoothed by applying the specific averaging kernels $\mathbf{A}$ and a priori profiles from the FTIR and MAX-DOAS retrievals, according to the formalism of Rodgers and Connor (2003) and Eq. 1. The averaging kernels used for the smoothing of the CTM output profiles are the averaging kernels obtained from the individual retrieved profiles, seasonally-averaged over spring (from March to May), summer (from June to August), fall (from September to November) and winter (from December to February) throughout the entire investigated time period.

Further in this work, the comparisons between smoothed CTM outputs and ground-based retrieval products are carried out only for the days with observations available, i.e., 261 days for FTIR and 440 days for MAX-DOAS. Given the MAX-DOAS vertical sensitivity, only partial columns of $\mathrm{HCHO}$ simulated by the models between the 3.6 and $8 \mathrm{~km}$ altitude range are confronted by MAX-DOAS retrieval products, while the comparisons between CTM and FTIR data involve the total columns (representing approximately the tropospheric column). In order to show that the FTIR and MAXDOAS measurements are complementary for HCHO measurements at Jungfraujoch, we have added to Figs. 4, 6 and 7, involving the FTIR and MAX-DOAS columns the HCHO concentration retrieved by MAX-DOAS for the $3.6-3.8 \mathrm{~km}$ near-surface layer, i.e., the first $200 \mathrm{~m}$ thick layer directly above the station, where the MAX-DOAS is highly sensitive (see Sect. 3.1).

\subsection{Seasonal modulation of formaldehyde}

The monthly mean HCHO abundances over the July 2010December 2012 period and associated $1 \sigma \mathrm{SD}$, displayed on a 1-year time base, are provided in Fig. 4, with the FTIR total columns (in red) and the MAX-DOAS 3.6-8 km partial columns (in purple) in Fig. 4a and b, respectively. The HCHO concentration for the $3.6-3.8 \mathrm{~km}$ layer according to MAXDOAS is presented in Fig. 4c. The thick solid lines correspond to a running mean fit of the daily average data, with a 15-day step and a 2-month-wide integration time, while the shaded areas represent the $1 \sigma \mathrm{SD}$ around the running mean curve. The running mean fits and the associated $1 \sigma \mathrm{SD}$ of the GEOS-Chem (in blue) and IMAGES (in green) HCHO outputs smoothed by the FTIR (in Fig. 4a) and MAX-DOAS (in Fig. $4 \mathrm{~b}$ and c) seasonal averaging kernels have been added to Fig. 4 as thick solid lines and thin curves, respectively.

According to Fig. 4, HCHO amounts retrieved from the ground-based FTIR and MAX-DOAS observations at the ISSJ present a clear and consistent seasonal cycle, characterized by a summertime maximum in July-August and a late winter minimum. The running mean total columns from FTIR observations range from $0.92 \pm 0.30$ to $2.19 \pm$ $0.72 \times 10^{15}$ molec cm $^{-2}$, representing a seasonal amplitude of $83 \%$ (defined here as the difference between the maximum and the minimum running means, divided by the annual average over the investigated period), and the running means of partial columns from MAX-DOAS vary between $0.75 \pm 0.19$ and $1.43 \pm 0.45 \times 10^{15}$ molec cm$^{-2}$, representing a seasonal amplitude of $66 \%$, slightly weaker than in the FTIR results. It is worth noting that the seasonal amplitude calculated on the basis of the MAX-DOAS HCHO concentration within the $3.6-3.8 \mathrm{~km}$ altitude range equals $\sim 130 \%$, highlighting the strong sensitivity of this instrument to the near-surface layer.

Ground-based FTIR HCHO observations have already been performed at NDACC sites located at different latitudes. Such FTIR measurements have shown a good overall agreement when compared with $\mathrm{HCHO}$ observed from space by GOME (Jones et al., 2009), ACE-FTS (Viatte et al., 2014) and SCIAMACHY (Vigouroux et al., 2009). However, it appears firstly that differences in altitude affect the direct comparisons between these ground-based sites and the 

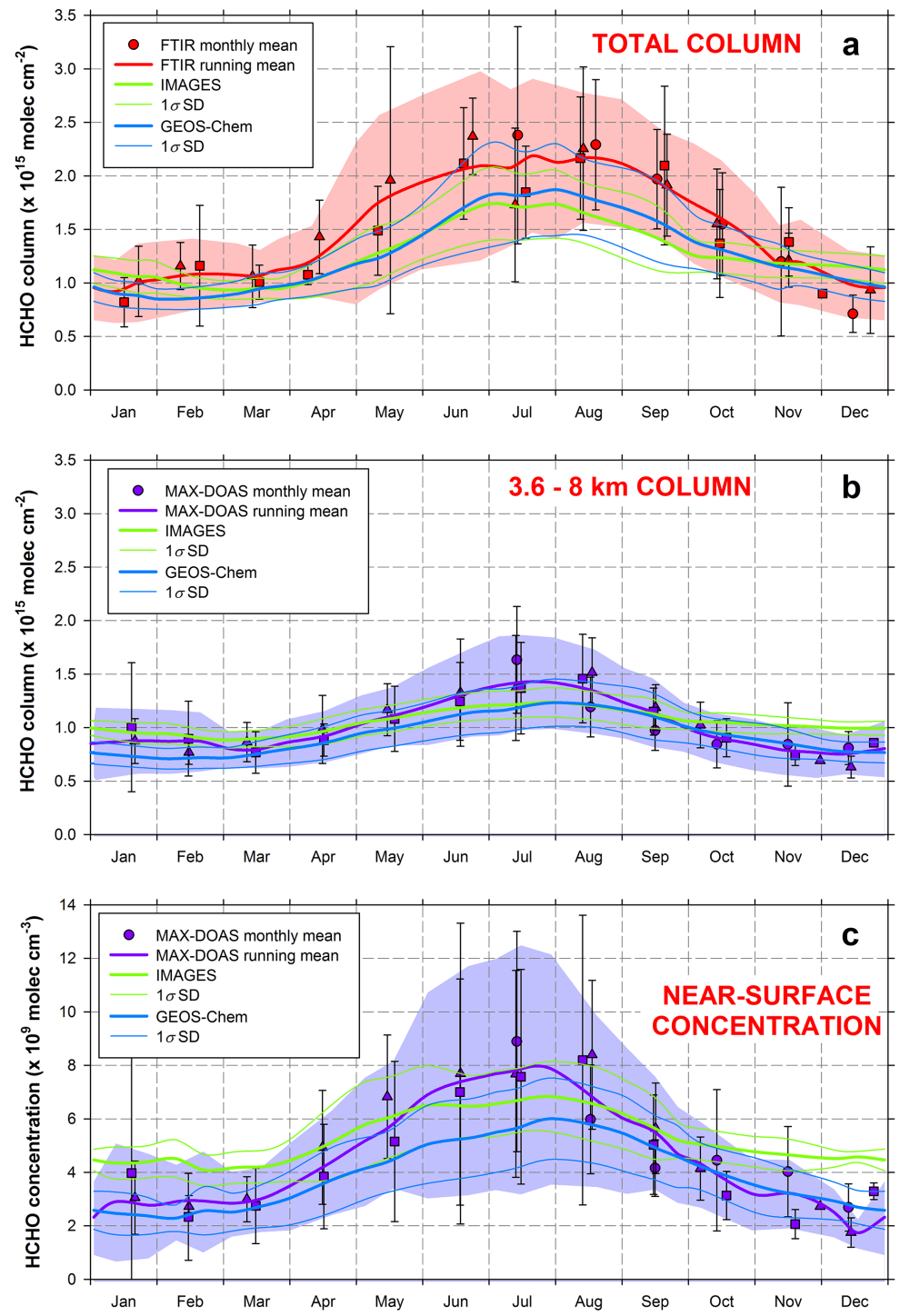

Figure 4. Monthly-mean column abundances of $\mathrm{HCHO}$ and associated $1 \sigma \mathrm{SD}$ bars displayed on a 1-year time base, according to the FTIR and MAX-DOAS retrievals (a and b, respectively) above Jungfraujoch from July 2010 to December 2012. The circle, triangle and square dots correspond to the monthly means from 2010, 2011 and 2012, respectively. The thick curves correspond to a running mean fit to the daily-mean columns displayed on a 1-year time base (not shown here), with a 15-day step and a 2-month-wide integration time. The shaded areas represent the $1 \sigma \mathrm{SD}$ associated with the running mean curves. As it is calculated on the basis of the daily-mean columns, this $1 \sigma \mathrm{SD}$ convolves interannual variability and variability of the monthly mean. Note that the FTIR abundances correspond to total columns and the MAX-DOAS data consist of partial columns within the $3.6-8 \mathrm{~km}$ altitude range. The HCHO amounts calculated from the smoothed CTM profiles are displayed in each frame as running mean fit (solid thick curve) and the associated $1 \sigma \mathrm{SD}$ (thin line). A similar figure, but for the $\mathrm{HCHO}$ concentration derived from MAX-DOAS and the CTMs within the 3.6-8 km near-surface layer, is drawn in (c).

ISSJ. Viatte et al. (2014) measured HCHO total columns in the Arctic at another background site in Eureka, Canada $\left(80.0^{\circ} \mathrm{N}, 86.4^{\circ} \mathrm{W}, 610 \mathrm{~m}\right.$ a.s.l. $)$, and reported monthly averaged values over the 5-year period 2007-2011 from 0.27 to $3.14 \times 10^{15}$ molec $\mathrm{cm}^{-2}$. The total columns derived from the FTIR data set of Jungfraujoch are consistent with the measurements from Eureka, given that the strong vertical gradient of HCHO concentration in the troposphere and the ISSJ elevation contribute to the relatively lower $\mathrm{HCHO}$ amounts retrieved at Jungfraujoch. Moreover, Viatte et al. (2014) reported a seasonal cycle characterized by an amplitude of $93 \%$ at Eureka, in agreement with the ISSJ FTIR observations. It is difficult to compare the ISSJ with other background sites because many of them experience enhancements in $\mathrm{HCHO}$ concentration resulting from distant anthropogenic activity and biomass burning. For example, Notholt et al. 
(1997) reported higher monthly mean total columns between 1.67 and $4.25 \times 10^{15}$ molec $\mathrm{cm}^{-2}$ at Ny Ålesund, Spitsbergen $\left(78.9^{\circ} \mathrm{N}, 11.9^{\circ} \mathrm{E}, 15 \mathrm{~m}\right.$ a.s.l.), for the $1992-1995$ time period, as well as a second maximum during winter. Part of these differences compared to the ISSJ results might be explained by the updated spectroscopic line intensities for HCHO in HITRAN 2008 (Perrin et al., 2009) used in this study, increased by approximately $30 \%$ compared to the previous HITRAN compilations and hence decreasing the retrieved total columns, added to the fact that direct transport of pollutants from Europe to Ny Alesund occurs especially during winter. In the Southern Hemisphere, Jones et al. (2009) presented monthly mean total columns varying between 1.5 and $4.0 \times 10^{15}$ molec $\mathrm{cm}^{-2}$ for the $1992-2005$ period at Lauder, New Zealand ( $45.0^{\circ} \mathrm{S}, 169.7^{\circ} \mathrm{E}, 370 \mathrm{~m}$ a.s.1.), and Vigouroux et al. (2009) retrieved values ranging from 1.5 to $7.0 \times 10^{15}$ molec $\mathrm{cm}^{-2}$ at Saint-Denis, Reunion Island (20.9 ${ }^{\circ} \mathrm{S}, 55.5^{\circ} \mathrm{E}, 10 \mathrm{~m}$ a.s.1.), during 2004-2007 campaigns, both sites being largely influenced by long-range transport of biomass burning plumes and $\mathrm{HCHO}$ precursors originating from Australia and Africa/Madagascar, respectively.

The seasonal variability of HCHO observed by both FTIR and MAX-DOAS instruments (Fig. 4) is consistent with the annual variations of the atmospheric photochemistry as well as with the annual cycle of biogenic emissions at Northern Hemisphere mid-latitudes and more specifically over Europe (see Dufour et al., 2009b; Curci et al., 2010) and above Jungfraujoch (see Legreid et al., 2008, and references therein). Indeed, on an overall scale over Europe, the background of HCHO throughout the year is supplied by oxidation of $\mathrm{CH}_{4}$ and other long-lived VOCs (Dufour et al., 2009b; Curci et al., 2010). In summer, enhanced temperatures and insolation induce a higher photochemical oxidation rate of VOCs by the $\mathrm{OH}$ radicals, which results in increasing the $\mathrm{HCHO}$ formation. Moreover, the summer periods are also characterized by large biogenic emissions of NMVOCs that are high-yield HCHO precursors, such as isoprene, taking place in the continental boundary layer and originating from plants and temperate forests during the growing season in the Northern Hemisphere (e.g., Dufour et al., 2009b; Stavrakou et al., 2009a; Curci et al., 2010). More specifically at Jungfraujoch, Legreid et al. (2008) reported measurements of higher concentrations in NMVOCs during summertime, which are attributed to secondary oxidation processes and higher emissions from biogenic sources essentially originating from northern Italy (because of the higher biogenic activity in this region compared to the north of the Alps). As explained previously in Sect. 2.1, air masses containing such biogenic compounds might be transported from the boundary layer to the ISSJ by different atmospheric mechanisms (air advection, thermally driven convection, front passage and topographic venting) and eventually add to the NMVOC precursors of HCHO. For instance, Bader et al. (2014) recently highlighted the role of biogenic sources and plant growth, especially from the region south of the Alps, in the increase of methanol concentration, a high-yield precursor of $\mathrm{HCHO}$, during summertime at Jungfraujoch. Conversely, minima of HCHO amounts observed at the ISSJ (Fig. 4) are primarily due to the lower radiation and the relatively weak atmospheric moisture during winter, inducing lower concentrations of $\mathrm{OH}$ radicals and hence lower oxidation rates of VOCs. Nevertheless, more elevated concentrations in reactive compounds from anthropogenic origin (such as benzene, toluene and butane), which are potential precursors of $\mathrm{HCHO}$, were measured in winter at Jungfraujoch (Balzani Lööv et al., 2008; Legreid et al., 2008; Starokozhev et al., 2009) mainly because of their longer lifetimes and more intensive anthropogenic combustion during this season. Using a statistical trajectory model, Legreid et al. (2008) identified northern Italy, southern France and southern Germany (highly industrialized and populated areas) as the main contributors to these anthropogenic emissions.

Figure 4 shows that both GEOS-Chem and IMAGES models, smoothed by the specific averaging kernels of FTIR and MAX-DOAS, are able to reproduce the seasonal variations of HCHO above Jungfraujoch over the July 2010-December 2012 time period, showing a maximum in summer and a minimum in winter. However, both CTMs simulate on average lower HCHO amounts than the columns retrieved from FTIR (from March to October) and MAX-DOAS (from June to August) observations, although these differences are not significant given the $1 \sigma \mathrm{SD}$ associated with the ground-based measurements. In winter, HCHO abundances from GEOSChem are relatively weaker or equal to FTIR and MAXDOAS data, while IMAGES provides higher HCHO columns during this time period, especially in comparison with the MAX-DOAS partial columns. Such a difference can be explained by the fact that Jungfraujoch is sensitive to anthropogenic NMVOC emissions in winter and these differ between the two models. Indeed, total anthropogenic emissions over Europe (calculated within the $20^{\circ} \mathrm{W}-60^{\circ} \mathrm{E}$ and $36^{\circ} \mathrm{N}-$ $88^{\circ} \mathrm{N}$ area) for NMVOC species common to both models amount to 4.7 $\mathrm{TgC}^{-1}{ }^{-1}$ for GEOS-Chem and 15.7 $\mathrm{TgC}^{-1}$ for IMAGES. Consequently, the CTMs simulate lower seasonal amplitudes above Jungfraujoch - more precisely, 80, 56 and $94 \%$ for GEOS-Chem, and 63, 33 and 52\% for IMAGES - when successively compared to FTIR (83\%), $3.6-8 \mathrm{~km}$ MAX-DOAS (66\%) and 3.6-3.8 km MAX-DOAS $(130 \%)$ seasonal amplitudes, respectively. Ground-based observations from both remote sensing instruments systematically provide larger $1 \sigma \mathrm{SD}$ around the running mean curve than the models, especially during summertime. Indeed, the models dilute local enhancements in $\mathrm{HCHO}$ because of their relatively coarse spatial resolution.

The discrepancies between the FTIR and MAX-DOAS seasonal cycles of HCHO and the smoothed CTM outputs (reported in Table 4) have been estimated on the basis of the daily means over the entire July 2010-December 2012 time period by averaging the daily fractional differences (defined here as the difference between two columns divided 
Table 4. Mean fractional differences (in $\% \pm 1 \sigma$ ), calculated on the basis of daily-mean values, between the FTIR and MAX-DOAS HCHO columns (and near-surface concentration) and the CTM outputs for the July 2010-December 2012 time period above Jungfraujoch. These mean fractional differences are given for the comparisons involving the CTM profiles with and without smoothing by the FTIR and MAXDOAS averaging kernels.

\begin{tabular}{lccc}
\hline & FTIR total column & 3.6-8 km MAX-DOAS column & 3.6-3.8 km MAX-DOAS column \\
\hline With smoothing & & & \\
\hline IMAGES & $-12.7 \pm 36.2$ & $5.3 \pm 27.0$ & $22.8 \pm 44.6$ \\
GEOS-Chem & $-12.3 \pm 33.5$ & $-5.8 \pm 21.9$ & $-7.4 \pm 35.2$ \\
\hline Without smoothing & & & $23.3 \pm 44.2$ \\
\hline IMAGES & $-10.7 \pm 37.1$ & $7.9 \pm 27.4$ & $-9.9 \pm 35.0$ \\
GEOS-Chem & $-19.4 \pm 35.4$ & $-8.3 \pm 29.2$ & \\
\hline
\end{tabular}

by the average of these two columns) between the retrieved and the simulated HCHO columns (and concentrations in the near-surface layer). Such fractional difference aims at reducing the impact of the large $\mathrm{HCHO}$ columns in the overall comparison between the two data sets. Table 4 summarizes these mean fractional differences for comparisons involving the CTM outputs with and without smoothing by the FTIR and MAX-DOAS averaging kernels. These results show that smoothed GEOS-Chem columns underestimate both groundbased data sets and that smoothed IMAGES columns underestimate and overestimate the FTIR and MAX-DOAS data, respectively. Moreover, the smoothing generally appears to improve the comparisons between the CTMs and the groundbased data sets. When considered over the year as a whole, the $1 \sigma \mathrm{SD}$ associated with these mean fractional differences indicates that the discrepancies are not significant. Parts of these large errors are due to the inability of the models to reproduce the seasonal amplitude of $\mathrm{HCHO}$ abundances retrieved from FTIR and MAX-DOAS observations, as highlighted previously in Fig. 4.

In the present study, a direct comparison between the FTIR total columns and the MAX-DOAS 3.6-8 km partial columns would not be meaningful (see Sect. 3.1), but the CTM simulations of HCHO still allow for an estimation of the consistency between both ground-based retrievals. Indeed, the mean fractional differences between the models and the FTIR data as well as the mean fractional differences calculated between the models and the MAX-DOAS observations are embedded in the respective uncertainties of the ground-based measurements (see Table 2, 3 and 4). As the HCHO seasonal cycles derived from the same CTM simulations present similar discrepancies to the ground-based data sets when the CTM profiles are respectively smoothed by the FTIR and MAX-DOAS averaging kernels, this is an indication that the FTIR and MAX-DOAS retrievals are consistent between each other for HCHO above Jungfraujoch over the investigated time period.

\subsection{Formaldehyde concentration profiles}

Figure 5 displays the seasonal averages of the HCHO concentration profiles (in molec $\mathrm{cm}^{-3}$ ) above Jungfraujoch for the FTIR and MAX-DOAS data sets, as well as for smoothed CTM outputs, calculated on the basis of daily mean profiles over the entire July 2010-December 2012 time period. The shaded areas correspond to the $1 \sigma \mathrm{SD}$ around the mean seasonal profile retrieved from FTIR (in red) and MAX-DOAS (in purple) observations. In addition, the slope of each concentration profile has been determined from a linear regression of data points within the $3.6-7 \mathrm{~km}$ altitude range common to the vertical resolution of both FTIR and MAX-DOAS techniques.

As already presented by Fig. 4, Fig. 5 illustrates the seasonal modulations of the averaged retrieved profiles in the lower troposphere above Jungfraujoch for each measurement technique. This modulation explains the largest part of the seasonal variability observed in the $\mathrm{HCHO}$ columns derived from the ground-based measurements. At the ISSJ altitude, mean $\mathrm{HCHO}$ concentrations indeed vary between 3.0 and $7.0 \times 10^{9} \mathrm{molec} \mathrm{cm}^{-3}$ from wintertime to summertime according to the FTIR data set and up to $8.0 \times 10^{9}$ molec cm $\mathrm{cm}^{-3}$ for the summer mean MAX-DOAS profiles. Throughout the year, these concentrations decrease rapidly with altitude, down to between 1.5 and $2.0 \times 10^{9}$ molec $\mathrm{cm}^{-3}$ at $7 \mathrm{~km}$ altitude in the MAX-DOAS profile, which corresponds to the upper limit of vertical sensitivity for this instrument, and down to negligible values around $12 \mathrm{~km}$ altitude regarding the FTIR data.

The higher resolution of the MAX-DOAS profiles allows for a better representation of the first tropospheric layers directly above Jungfraujoch in comparison with FTIR. This higher resolution results in stronger variations of the slope values associated with the retrieved $\mathrm{HCHO}$ profiles and in generally larger standard deviations around the mean profile in the closest vicinity of the ISSJ within each seasonal time period. In predominant background conditions such as at Jungfraujoch, a significant part of the $\mathrm{HCHO}$ column is situated in the free troposphere $(\sim 25 \%$ on average is lo- 

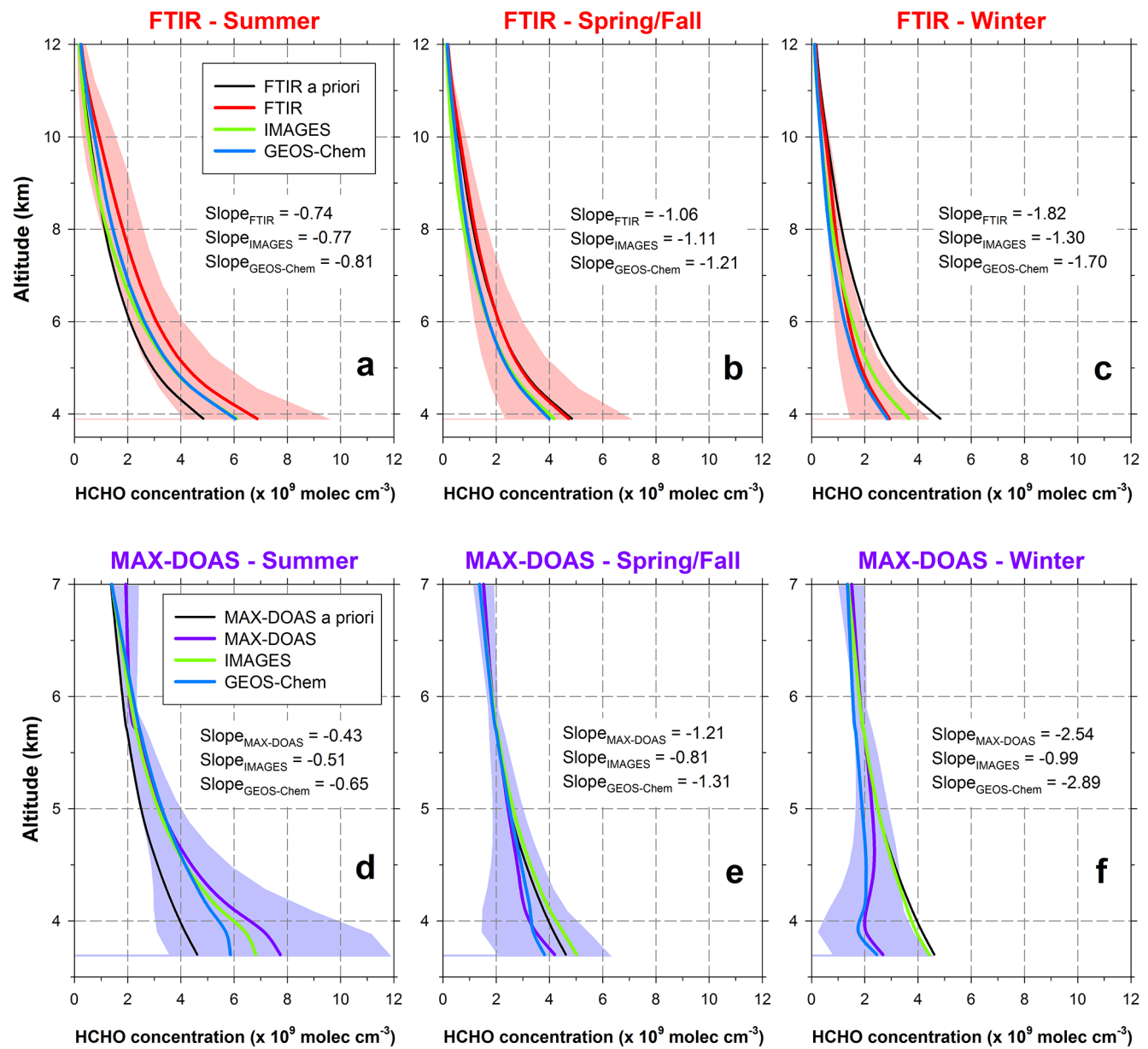

Figure 5. Mean seasonal profiles of HCHO concentration (in molec $\mathrm{cm}^{-3}$ ) above Jungfraujoch according to the FTIR and MAX-DOAS retrievals (upper and lower frames, respectively), calculated on the basis of the daily means over the July 2010-December 2012 time period. The shaded areas correspond to the $1 \sigma$ SD around the mean profiles. The smoothed profiles derived from the IMAGES (in green) and GEOSChem (in blue) simulations have been added to each frame. The mean slope of each profile has been estimated by adjusting a linear regression between 3.6 and $7 \mathrm{~km}$ altitude with the least mean squares method.

cated above $8 \mathrm{~km}$ ), while in most other NDACC sites the contribution of the column above $8 \mathrm{~km}$ to the total column is generally negligible due to lower elevation and more polluted conditions. As previously highlighted by the respective eigenvectors and averaging kernels of FTIR and MAXDOAS displayed in Fig. 3, both FTIR (because of its larger altitude range of sensitivity) and MAX-DOAS (due to its very high vertical resolution in the lowest tropospheric layers) are complementary and provide added-value measurements of HCHO distribution above Jungfraujoch.

The comparison between the smoothed CTM profiles and the ground-based retrievals presented in Fig. 5, as well as their associated slopes within the $3.6-7 \mathrm{~km}$ altitude range, confirms that both GEOS-Chem and IMAGES simulations tend to underestimate the retrieved $\mathrm{HCHO}$ abundances during summertime and that IMAGES overestimates it in winter. Regarding the spring and fall seasons, both models simulate slightly lower HCHO concentrations than FTIR, and
IMAGES still overestimates $\mathrm{HCHO}$ amounts compared to the MAX-DOAS observations. However, these mean profiles derived from the smoothed CTM outputs are generally embedded in the $1 \sigma \mathrm{SD}$ area of the ground-based data on the entire range of investigated altitudes, and hence the related biases are not significant at that level of uncertainty. It is worth noting that the anomalies of the CTM outputs relative to the FTIR profile extend throughout the column in summer, while the MAX-DOAS results imply that the largest discrepancies take place near the surface. This results from the differences of resolution between both instruments (see Sect. 3.1), the FTIR retrievals being sensitive up to $10-12 \mathrm{~km}$ and the MAX-DOAS profiles tending to reproduce the a priori above $5.5 \mathrm{~km}$. 

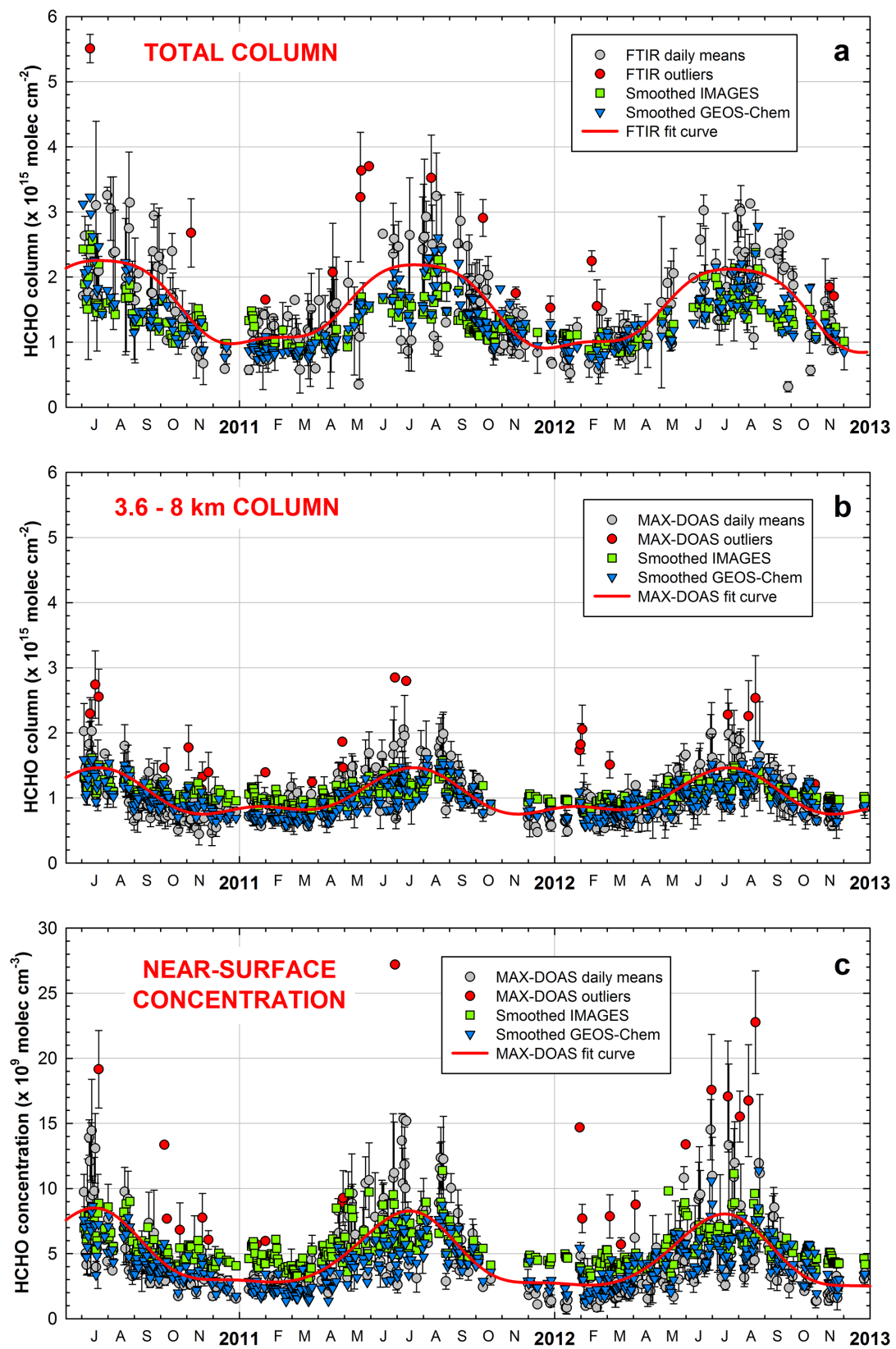

Figure 6. Time series of daily-mean HCHO abundances and the associated $1 \sigma$ SD bars from the FTIR (a) and MAX-DOAS (b) data sets. The solid thick curves (in red) represent the fitting function calculated by applying to the whole time series the statistical bootstrap resampling method from Gardiner et al. (2008). The daily-mean HCHO amounts from the smoothed IMAGES and GEOS-Chem models are displayed in green and blue, respectively. A similar figure, but for the HCHO concentration derived from MAX-DOAS and the CTMs within the 3.6$3.8 \mathrm{~km}$ near-surface layer, is drawn in (c). The outliers (red dots) correspond to daily observation values with relative anomalies to the curve fit calculated by Gardiner et al. (2008), higher than the 95th percentile value of all relative anomalies of the data set.

\subsection{Formaldehyde daily time series}

Figure 6 presents the July 2010-December 2012 time series of daily-averaged $\mathrm{HCHO}$ columns and the associated $1 \sigma \mathrm{SD}$, as retrieved from the FTIR and MAX-DOAS observations in Fig. 6a and b, respectively. The HCHO amounts consist of total tropospheric columns (FTIR) and in partial columns within the 3.6-8 km altitude range (MAX-DOAS) according to the vertical resolution and sensitivity of each remote sensing instrument. The daily mean outputs, derived from the HCHO profiles provided by both GEOS-Chem and IMAGES models and smoothed by applying the FTIR and MAX-DOAS averaging kernels, are drawn in blue and in green for the coincident days with the ground-based data sets. 

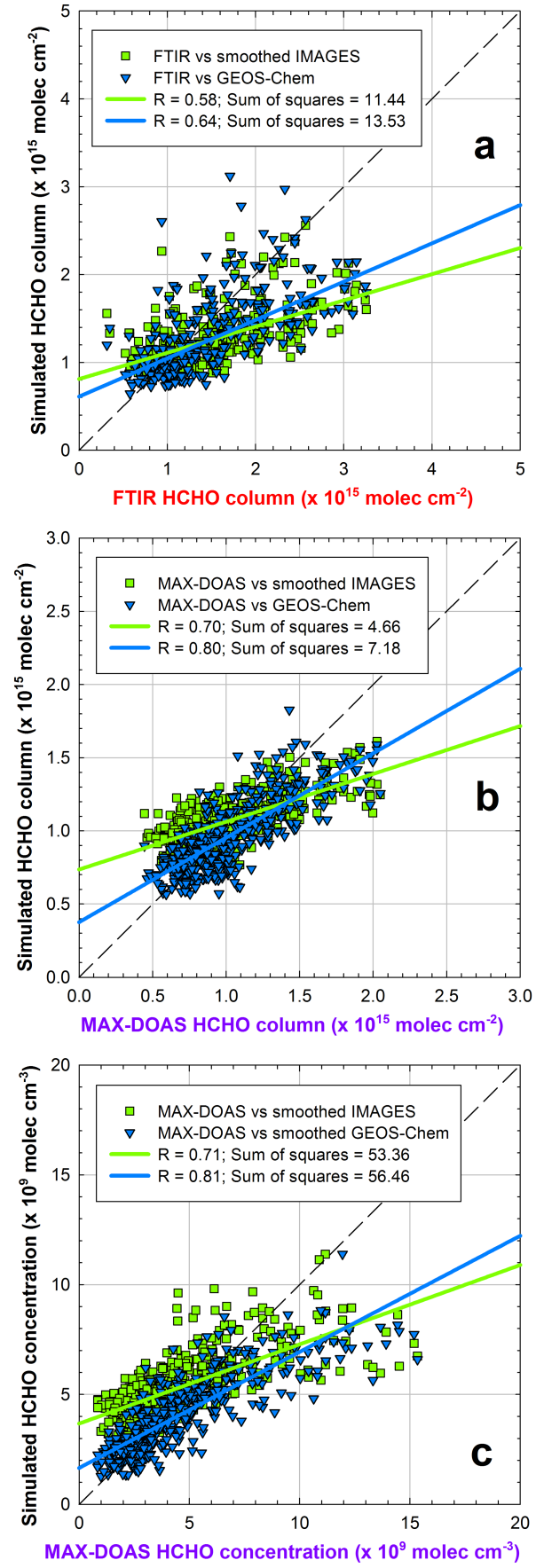

Figure 7. Direct comparisons between the FTIR and smoothed CTM daily-mean HCHO columns (a) and between the MAXDOAS and smoothed CTM daily-mean partial columns within the $3.6-8 \mathrm{~km}$ altitude range (b) displayed in Fig. 6 . The blue and green straight lines correspond to the linear regressions (with $R$ as the correlation) between the ground-based measurements and the model outputs. A similar figure, but for the $\mathrm{HCHO}$ concentration derived from MAX-DOAS and the CTMs within the 3.6-3.8 km nearsurface layer, is drawn in frame (c). Outliers identified as red dots in Fig. 6 have been discarded from the data sets.
The red solid thick curves represent the fitting of the whole time series by the statistical bootstrap resampling method (Gardiner et al., 2008), which is a combination of a linear function and a third-order Fourier series accounting for the intra-annual variability of the data set. The similar time series for the 3.6-3.8 km near-surface $\mathrm{HCHO}$ concentration derived from MAX-DOAS and both CTMs are drawn in Fig. 6c.

The daily-averaged total columns of $\mathrm{HCHO}$ retrieved from the FTIR solar spectra at the ISSJ vary between 0.32 and $5.51 \times 10^{15} \mathrm{molec} \mathrm{cm}^{-2}$. These values are consistent with total columns retrieved from FTIR solar spectra recorded at other NDACC sites (Notholt et al., 1997; Jones et al., 2009; Vigouroux et al., 2009; Viatte et al., 2014) given the ISSJ elevation and the dominance of weakly polluted air masses. For instance, Viatte et al. (2014) reported total column amounts ranging from 0.02 to $6.30 \times 10^{15}$ molec cm $^{-2}$ over a 5-year time series at Eureka. The MAX-DOAS time series present a minimum of partial column within the 3.6$8 \mathrm{~km}$ altitude range equal to $0.44 \times 10^{15} \mathrm{molec} \mathrm{cm}^{-2}$ and a maximum reaching $2.85 \times 10^{15} \mathrm{molec} \mathrm{cm}^{-2}$. The FTIR data set shows the larger seasonal amplitude (consistent with the seasonal modulation previously highlighted in Fig. 4) but also the higher dispersion around the fitting function, with an absolute mean fractional difference over the whole time period equal to $24.1 \%$ compared to $20.0 \%$ for the MAXDOAS time series. The minimum daily values during wintertime are approximately equal to $1.0 \times 10^{15} \mathrm{molec} \mathrm{cm}^{-2}$ with a small dispersion around this value for both FTIR and MAX-DOAS time series, indicating a dominant contribution of the first tropospheric layers to the total amounts of $\mathrm{HCHO}$ above Jungfraujoch during winter (80-90\%) and conversely a less significant contribution during summer (60-70\%).

These results show that the seasonal modulation of $\mathrm{HCHO}$ and its day-to-day variability (for the latter, solely in the case where the uncertainties on the FTIR measurements are consistent with the MAX-DOAS uncertainties) are not solely due the variability in the lower troposphere (Fig. 6b and c) where the MAX-DOAS instrument is the most sensitive. Conversely, part of the variability also takes place in higher tropospheric layers. Indeed, the $\mathrm{HCHO}$ formation in the upper troposphere might be seasonally enhanced by largescale atmospheric transport and/or convective fluxes bringing more precursor compounds to the upper layers (Stickler et al., 2006; Fried et al., 2008). In this latter case, such a variability may only be captured by the FTIR instrument owing to its more uniform vertical sensitivity throughout the troposphere compared to the MAX-DOAS, as indicated by the larger seasonal amplitude of the FTIR data set.

Finally, these results also suggest that the $\mathrm{HCHO}$ seasonality above Jungfraujoch is not solely influenced by the variations of photolysis and oxidation rate of $\mathrm{CH}_{4}$, otherwise this seasonal signal would affect homogeneously the entire column. Conversely, the HCHO seasonality and its day-today variability seem to be driven rather by incursions of NMVOC precursors from anthropogenic (especially in win- 
ter) and biogenic (as early in the year as March-April until late summer) sources through frequent injection of air parcels from boundary layer (see Sect. 2.1 and 4.1). A more detailed investigation of the different emission sources responsible for the HCHO seasonality and its day-to-day variability above Jungfraujoch is part of ongoing work involving FTIR decadal time series and CTM sensitivity runs.

The direct comparison performed between the FTIR and MAX-DOAS measurements and the HCHO columns derived from the smoothed profiles provided by GEOS-Chem and IMAGES, on the basis of the daily means, are drawn in Fig. $7 \mathrm{a}$ and b. The similar comparison involving $\mathrm{HCHO}$ concentration in the $3.6-3.8 \mathrm{~km}$ near-surface layer is presented in Fig. 7c. In order to improve these comparisons, some outliers, probably due to transport of air masses with high NMVOC precursor concentrations, have been discarded because the models are generally unable to reproduce such events. These outliers correspond to daily observation values with relative anomalies to the curve fit calculated by Gardiner et al. (2008) higher than the 95th percentile value of all relative anomalies of the data set. These outliers are identified for each time series as red dots in Fig. 6. The correlations between the 3.6-8 $\mathrm{km}$ MAX-DOAS data set and the models $(R=0.80$ and 0.70 with GEOS-Chem and IMAGES, respectively; Fig. 7b) are better than those between FTIR measurements and smoothed CTM outputs $(R=0.64$ and 0.58; Fig. 7a). The similar correlations but for comparisons involving the discarded outliers are 0.75 and 0.63 for MAX-DOAS versus GEOS-Chem and IMAGES, respectively, and 0.62 and 0.57 for FTIR versus GEOS-Chem and IMAGES. Although most of the large differences between the model data and the ground-based observations occur for daily means in summer or during the spring/fall season, tests have shown that these differences are not significantly related to a more particular time period of the year. Since considering only the errors associated with the HCHO columns retrieved from ground-based observations cannot explain all the observed biases between models and both FTIR and MAX-DOAS, these results also suggest that part of these discrepancies might be due to a day-to-day variability of the $\mathrm{HCHO}$ columns not captured by the model simulations above Jungfraujoch.

\section{Conclusions}

In the present study, we have described strategies for $\mathrm{HCHO}$ retrieval performed at the high-altitude remote station of Jungfraujoch, derived from ground-based FTIR solar spectra and UV-visible MAX-DOAS scans recorded during the July 2010-December 2012 time period. HCHO profiles and the corresponding column amounts have been derived from FTIR measurements using four microwindows that encompass the $2760-2860 \mathrm{~cm}^{-1}$ spectral domain (based on Vigouroux et al., 2009) according to an OEM retrieval process. The MAX-DOAS strategy consists of deriving DSCDs by spectral fitting in the $328.5-358.0 \mathrm{~nm}$ wavelength range and then in applying an OEM-based profiling method on the DSCDs to produce HCHO vertical profiles. Characterization of the retrieval products has revealed different vertical resolution and sensitivity between both remote sensing instruments. Indeed, most of the information on the vertical distribution of HCHO contained in the MAX-DOAS measurements is located in the first tropospheric layers above the ISSJ (below $5.5 \mathrm{~km}$ altitude) with a maximum sensitivity in the lowest layers close to the ground, while FTIR retrievals are mainly sensitive in the free troposphere (up to $12 \mathrm{~km}$ altitude) and vertically unresolved. Such a difference of vertical resolution does not allow direct comparisons of FTIR and MAX-DOAS data sets. Therefore we have successively confronted FTIR total columns and MAX-DOAS $3.6-8 \mathrm{~km}$ partial columns as well as the corresponding vertical profiles to HCHO columns and profiles simulated by two state-of-the-art three-dimensional CTMs: GEOS-Chem and IMAGES v2. The vertical sensitivity specific to each groundbased instrument has been taken into account by convolving the HCHO profiles produced by the CTMs above Jungfraujoch over the whole investigated time period by the FTIR and MAX-DOAS AVKs, respectively.

Analysis of such comparisons has indicated that HCHO profiles and the corresponding columns derived from both ground-based remote sensing techniques show consistent seasonal modulation at the ISSJ over the July 2010December 2012 time period, characterized by summertime maximum and wintertime minimum. A dominant contribution of the first tropospheric layers to the total column of HCHO has been highlighted in winter (80-90\%), while this contribution has been slightly dampened in summer (60$70 \%$ ). Considering that the FTIR data set has presented higher seasonal amplitude than MAX-DOAS results, this suggests that seasonal modulation of HCHO (as well as its day-to-day variability) is not solely driven by lowertropospheric variability but also influenced by $\mathrm{HCHO}$ variability occurring in higher tropospheric layers, mainly reproduced by the FTIR retrievals. Moreover, when compared to the FTIR and MAX-DOAS measurements, the CTM outputs have shown discrepancies embedded in the respective uncertainties of the ground-based measurements, i.e., mainly an underestimation in summer for both models. These results indicate a consistency between the HCHO retrievals from both remote sensing techniques as well as their complementarity for studying the vertical distribution of $\mathrm{HCHO}$ above Jungfraujoch.

Due to its remote location and its altitude, the ISSJ often allows investigation of atmospheric background conditions and is characterized by low HCHO. For example, layers above $8 \mathrm{~km}$ altitude contribute approximately $25 \%$ to the total column above Jungfraujoch, while this contribution remains generally negligible at other NDACC stations. Therefore, the FTIR and MAX-DOAS data sets used in the present study and combined with CTM outputs have the potential to 
provide an important background test site for investigating the vertical HCHO distribution, e.g., for satellite retrievals.

The seasonal modulation of HCHO above Jungfraujoch is not solely driven by the variation of the photo-oxidation rate of $\mathrm{CH}_{4}$. Although the ISSJ is mainly located in the free troposphere, frequent injections of air masses from the boundary layer due to different mechanisms such as tropospheric venting, front passage and thermally driven convection may indeed occur, especially during summertime, bringing NMVOC precursors of HCHO from anthropogenic and biogenic emission sources to Jungfraujoch (e.g., Lugauer et al., 2000; Henne et al., 2004, 2005; Li et al., 2005; Legreid et al., 2008). Therefore, further work is required to identify and estimate the contribution of the different NMVOCs to the HCHO formation at the ISSJ.

The present study describes and validates an optimized FTIR strategy for HCHO retrieval at Jungfraujoch. This strategy is implemented in an ongoing work which aims at exploiting the multi-decadal observational time series of FTIR solar spectra available at the ISSJ (back to 1988) in order to investigate interannual variability and produce a long-term trend of HCHO. Little has been observed about the intra-day variability of $\mathrm{HCHO}$; such a multi-decadal time series will also be helpful to consider this issue.

Further investigations involving sensitivity runs are also needed to explain why the observed $\mathrm{HCHO}$ amounts are underestimated by GEOS-Chem and IMAGES in summer above Jungfraujoch. Such sensitivity runs are beyond the scope of this study, which mainly focuses on the retrieval strategies. However, preliminary tests have already suggested that the $\mathrm{HCHO}$ concentration simulated by the CTMs at the ISSJ is strongly influenced by different emission sources implemented by the models. Moreover, after comparison with $\mathrm{HCHO}$ amounts retrieved from space-based ACE-FTS measurements, Dufour et al. (2009b) reported that GEOS-Chem and LMDz-INCA (INteractive Chemistry and Aerosols) underestimate the summer maximum over Europe (and Russia) due to large uncertainties remaining in the emissions of $\mathrm{HCHO}$ precursors.

\section{The Supplement related to this article is available online at doi:10.5194/amt-8-1733-2015-supplement.}

Acknowledgements. The contributions of University of Liège and BIRA-IASB have been mainly supported by the PRODEX project ACROSAT funded by the Belgian Science Policy Office (BELSPO). The F.R.S.-FNRS and the Fédération Wallonie Bruxelles contributed to observational activities support. E. Mahieu is a research associate with F.R.S.-FNRS. The Swiss GAW-CH program is further acknowledged. We are grateful to the International Foundation High Altitude Research Stations Jungfraujoch and Gornergrat (HFSJG, Bern) for supporting the facilities needed to perform the observations. We further acknowledge the vital contribution from all the Belgian colleagues in performing the Jungfraujoch FTIR observations used here. This research was also financially supported at ULg and BIRA-IASB by the EU 7th Framework Programme projects NORS (contract 284421) and AGACC-II (BELSPO, Brussels) and at BIRA-IASB by the FP7 project ACTRIS (contract 262254).

Edited by: R. Volkamer

\section{References}

Atkinson, R.: Atmospheric chemistry of VOCs and $\mathrm{NO}_{x}$, Atmos. Environ., 34, 2063-2101, doi:10.1016/S1352-2310(99)00460-4, 2000.

Bader, W., Stavrakou, T., Muller, J.-F., Reimann, S., Boone, C. D., Harrison, J. J., Flock, O., Bovy, B., Franco, B., Lejeune, B., Servais, C., and Mahieu, E.: Long-term evolution and seasonal modulation of methanol above Jungfraujoch $\left(46.5^{\circ} \mathrm{N}, 8.0^{\circ} \mathrm{E}\right)$ : optimisation of the retrieval strategy, comparison with model simulations and independent observations, Atmos. Meas. Tech., 7, 3861-3872, doi:10.5194/amt-7-3861-2014, 2014.

Balzani Lööv, J. M., Henne, S., Legreid, G., Staehelin, J., Reimann, S., Prévôt, A. S. H., Steinbacher, M., and Vollmer, M. K.: Estimation of background concentrations of trace gases at the Swiss Alpine site Jungfraujoch (3580 ma.s.1.), J. Geophys. Res., 113, D22305, doi:10.1029/2007JD009751, 2008.

Bernath, P. F., McElroy, C. T., Abrams, M. C., Boone, C. D., Butler, M., Camy-Peyret, C., Carleer, M., Clerbaux, C., Coheur, P.F., Colin, R., DeCola, P., De Mazière, M., Drummond, J. R., Dufour, D., Evans, W. F. J., Fast, H., Fussen, D., Gilbert, K., Jennings, D. E., Llewellyn, E. J., Lowe, R. P., Mahieu, E., McConnell, J. C., McHugh, M., McLeod, S. D., Michaud, R., Midwinter, C., Nassar, R., Nichitiu, F., Nowlan, C., Rinsland, C. P., Rochon, Y. J., Rowlands, N., Semeniuk, K., Simon, P., Skelton, R., Sloan, J. J., Soucy, M.-A., Strong, K., Tremblay, P., Turnbull, D., Walker, K. A., Walkty, I., Wardle, D. A., Wehrle, V., Zander, R., and Zou, J.: Atmospheric Chemistry Experiment (ACE): mission overview, Geophys. Res. Lett., 32, L15S01, doi:10.1029/2005GL022386, 2005.

Bey, I., Jacob, D. J., Yantosca, R. M., Logan, J. A., Field, B. D., Fiore, A. M., Li, Q., Liu, H. Y., Mickley, L. J., and Schultz, M. G.: Global modeling of tropospheric chemistry with assimilated meteorology: model description and evaluation, J. Geophys. Res.-Atmos., 106, 23073-23095, doi:10.1029/2001JD000807, 2001.

Bogumil, K., Orphal, J., Homann, T., Voigt, S., Spietz, P., Fleischmann, O. C., Vogel, A., Hartmann, M., Bovensmann, H., Frerik, J., and Burrows, J. P.: Measurements of molecular absorption spectra with the SCIAMACHY Pre-Flight Model: Instrument characterization and reference spectra for atmospheric remote sensing in the $230-2380 \mathrm{~nm}$ region, J. Photoch. Photobio. A, 157, 167-184, 2003.

Carlier, P., Hannachi, H., and Mouvier, G.: The chemistry of carbonyl compounds in the atmosphere: a review, Atmos. Environ., 20, 2079-2099, doi:10.1016/0004-6981(86)90304-5, 1986. 
Chance, K. V. and Spurr, R. J.: Ring effect studies: Rayleigh scattering, including molecular parameters for rotational Raman scattering, and the Fraunhofer spectrum, Appl. Optics, 36, 52245230, 1997.

Chang, L., Palo, S., Hagan, M., Richter, J., Garcia, R., Riggin, D., and Fritts, D.: Structure of the migrating diurnal tide in the Whole Atmosphere Community Climate Model (WACCM), Adv. Space Res., 41, 1398-1407, doi:10.1016/j.asr.2007.03.035, 2008.

Clémer, K., Van Roozendael, M., Fayt, C., Hendrick, F., Hermans, C., Pinardi, G., Spurr, R., Wang, P., and De Mazière, M.: Multiple wavelength retrieval of tropospheric aerosol optical properties from MAXDOAS measurements in Beijing, Atmos. Meas. Tech., 3, 863-878, doi:10.5194/amt-3-863-2010, 2010.

Collaud Coen, M., Weingartner, E., Furger, M., Nyeki, S., Prévôt, A. S. H., Steinbacher, M., and Baltensperger, U.: Aerosol climatology and planetary boundary influence at the Jungfraujoch analyzed by synoptic weather types, Atmos. Chem. Phys., 11, 5931-5944, doi:10.5194/acp-11-5931-2011, 2011.

Curci, G., Palmer, P. I., Kurosu, T. P., Chance, K., and Visconti, G.: Estimating European volatile organic compound emissions using satellite observations of formaldehyde from the Ozone Monitoring Instrument, Atmos. Chem. Phys., 10, 11501-11517, doi:10.5194/acp-10-11501-2010, 2010.

De Smedt, I., Stavrakou, T., Müller, J.-F., van der A. R. J., and Van Roozendael, M.: Trend detection in satellite observations of formaldehyde tropospheric columns, Geophys. Res. Lett., 37, L18808, doi:10.1029/2010GL044245, 2010.

Dufour, G., Szopa, S., Barkley, M. P., Boone, C. D., Perrin, A., Palmer, P. I., and Bernath, P. F.: Global uppertropospheric formaldehyde: seasonal cycles observed by the ACE-FTS satellite instrument, Atmos. Chem. Phys., 9, 38933910, doi:10.5194/acp-9-3893-2009, 2009a.

Dufour, G., Wittrock, F., Camredon, M., Beekmann, M., Richter, A., Aumont, B., and Burrows, J. P.: SCIAMACHY formaldehyde observations: constraint for isoprene emission estimates over Europe?, Atmos. Chem. Phys., 9, 1647-1664, doi:10.5194/acp-91647-2009, 2009b.

Fleischmann, O. C., Hartmann, M., Burrows, J. P., and Orphal, J.: New ultraviolet absorption cross-sections of $\mathrm{BrO}$ at atmospheric temperatures measured by time-windowing Fourier transform spectroscopy, J. Photoch. Photobio. A, 168, 117-132, 2004.

Fried, A., McKeen, S., Sewell, S., Harder, J., Henry, B., Goldan, P., Kuster, W., Williams, E., Baumann, K., Shetter, R., and Cantrell, C.: Photochemistry of formaldehyde during the 1993 Tropospheric OH Photochemistry Experiment, J. Geophys. Res.Atmos., 102, 6283-6296, doi:10.1029/96JD03249, 1997.

Fried, A., Crawford, J., Olson, J., Walega, J., Potter, W., Wert, B., Jordan, C., Anderson, B., Shetter, R., Lefer, B., Blake, D., Blake, N., Meinardi, S., Heikes, B., O’Sullivan, D., Snow, J., Fuelberg, H., Kiley, C. M., Sandholm, S., Tan, D., Sachse, G., Singh, H., Faloona, I., Harward, C. N., and Carmichael, G. R.: Airborne tunable diode laser measurements of formaldehyde during TRACE-P: distributions and box-model comparisons, J. Geophys. Res., 108, 8798, doi:10.1029/2003JD003451, 2003.

Fried, A., Olson, J. R., Walega, J. G., Crawford, J. H., Chen, G., Weibring, P., Richter, D., Roller, C., Tittel, F., Porter, M., Fuelberg, H., Halland, J., Bertram, T. H., Cohen, R. C., Pickering, K., Heikes, B. G., Snow, J. A., Shen, H., O'Sullivan, D. W., Brune, W. H., Ren, X., Blake, D. R., Blake, N., Sachse, G.,
Diskin, G. S., Podolske, J., Vay, S. A., Shetter, R. E., Hall, S. R., Anderson, B. E., Thornhill, L., Clark, A. D., McNaughton, C. S., Singh, H. B., Avery, M. A., Huey, G., Kim, S., and Millet, D. B.: Role of convection in redistributing formaldehyde to the Upper Troposphere over North America and the North Atlantic during the Summer 2004 INTEX campaign, J. Geophys. Res., 113, D17306, doi:10.1029/2007JD009760, 2008.

Fried, A., Cantrell, C., Olson, J., Crawford, J. H., Weibring, P., Walega, J., Richter, D., Junkermann, W., Volkamer, R., Sinreich, R., Heikes, B. G., O’Sullivan, D., Blake, D. R., Blake, N., Meinardi, S., Apel, E., Weinheimer, A., Knapp, D., Perring, A., Cohen, R. C., Fuelberg, H., Shetter, R. E., Hall, S. R., Ullmann, K., Brune, W. H., Mao, J., Ren, X., Huey, L. G., Singh, H. B., Hair, J. W., Riemer, D., Diskin, G., and Sachse, G.: Detailed comparisons of airborne formaldehyde measurements with box models during the 2006 INTEX-B and MILAGRO campaigns: potential evidence for significant impacts of unmeasured and multigeneration volatile organic carbon compounds, Atmos. Chem. Phys., 11, 11867-11894, doi:10.5194/acp-11-11867-2011, 2011.

Frieß, U., Monks, P. S., Remedios, J. J., Rozanov, A., Sinreich, R., Wagner, T., and Platt, U.: MAX-DOAS $\mathrm{O}_{4}$ measurements: a new technique to derive information on atmospheric aerosols: 2. Modeling studies, J. Geophys. Res., 111, D14203, doi:10.1029/2005jd006618, 2006.

Fu, T.-M., Jacob, D. J., Palmer, P. I., Chance, K., Wang, Y. X., Barletta, B., Blake, D. R., Stanton, J. C., and Pilling, M. J.: Space-based formaldehyde measurements as constraints on volatile organic compound emissions in east and south Asia and implications for ozone, J. Geophys. Res., 112, D06312, doi:10.1029/2006JD007853, 2007.

Gardiner, T., Forbes, A., de Mazière, M., Vigouroux, C., Mahieu, E., Demoulin, P., Velazco, V., Notholt, J., Blumenstock, T., Hase, F., Kramer, I., Sussmann, R., Stremme, W., Mellqvist, J., Strandberg, A., Ellingsen, K., and Gauss, M.: Trend analysis of greenhouse gases over Europe measured by a network of ground-based remote FTIR instruments, Atmos. Chem. Phys., 8, 6719-6727, doi:10.5194/acp-8-6719-2008, 2008.

Gielen, C., Van Roozendael, M., Hendrick, F., Pinardi, G., Vlemmix, T., De Bock, V., De Backer, H., Fayt, C., Hermans, C., Gillotay, D., and Wang, P.: A simple and versatile cloudscreening method for MAX-DOAS retrievals, Atmos. Meas. Tech., 7, 3509-3527, doi:10.5194/amt-7-3509-2014, 2014.

Grainger, J. and Ring, J.: Anomalous Fraunhofer line profiles, Nature, 193, p. 762, doi:10.1038/193762a0, 1962.

Guenther, A., Karl, T., Harley, P., Wiedinmyer, C., Palmer, P. I., and Geron, C.: Estimates of global terrestrial isoprene emissions using MEGAN (Model of Emissions of Gases and Aerosols from Nature), Atmos. Chem. Phys., 6, 3181-3210, doi:10.5194/acp-63181-2006, 2006.

Hak, C., Pundt, I., Trick, S., Kern, C., Platt, U., Dommen, J., Ordóñez, C., Prévôt, A. S. H., Junkermann, W., Astorga-Lloréns, C., Larsen, B. R., Mellqvist, J., Strandberg, A., Yu, Y., Galle, B., Kleffmann, J., Lörzer, J. C., Braathen, G. O., and Volkamer, R.: Intercomparison of four different in-situ techniques for ambient formaldehyde measurements in urban air, Atmos. Chem. Phys., 5, 2881-2900, doi:10.5194/acp-5-2881-2005, 2005.

Harder, J. W., Fried, A., Sewell, S., and Henry, B.: Comparison of tunable diode laser and long-path ultraviolet/visible spectroscopic measurements of ambient formaldehyde concentrations 
during the $1993 \mathrm{OH}$ Photochemistry Experiment, J. Geophys. Res., 102, 6267-6282, doi:10.1029/96JD01731, 1997.

Hase, F., Hannigan, J. W., Coffey, M. T., Goldman, A., Höpfner, M., Jones, N. B., Rinsland, C. P., and Wood, S. W.: Intercomparison of retrieval codes used for the analysis of high-resolution, ground-based FTIR measurements, J. Quant. Spectrosc. Ra., 87, 25-52, doi:10.1016/j.jqsrt.2003.12.008, 2004.

Heckel, A., Richter, A., Tarsu, T., Wittrock, F., Hak, C., Pundt, I., Junkermann, W., and Burrows, J. P.: MAX-DOAS measurements of formaldehyde in the Po-Valley, Atmos. Chem. Phys., 5, 909918, doi:10.5194/acp-5-909-2005, 2005.

Hendrick, F., Müller, J.-F., Clémer, K., Wang, P., De Mazière, M., Fayt, C., Gielen, C., Hermans, C., Ma, J. Z., Pinardi, G., Stavrakou, T., Vlemmix, T., and Van Roozendael, M.: Four years of ground-based MAX-DOAS observations of HONO and $\mathrm{NO}_{2}$ in the Beijing area, Atmos. Chem. Phys., 14, 765-781, doi:10.5194/acp-14-765-2014, 2014.

Henne, S., Furger, M., Nyeki, S., Steinbacher, M., Neininger, B., de Wekker, S. F. J., Dommen, J., Spichtinger, N., Stohl, A., and Prévôt, A. S. H.: Quantification of topographic venting of boundary layer air to the free troposphere, Atmos. Chem. Phys., 4, 497509, doi:10.5194/acp-4-497-2004, 2004.

Henne, S., Dommen, J., Neininger, B., Reimann, S., Staehelin, J., and Prévôt, A. S. H.: Influence of mountain venting in the Alps on the ozone chemistry of the lower free troposphere and the European pollution export, J. Geophys. Res., 110, D22307, doi:10.1029/2005JD005936, 2005.

Herndon, S. C., Jayne, J. T., Zahniser, M. S., Worsnop, D. R., Knighton, B., Alwine, E., Lamb, B. K., Zavala, M., Nelson, D. D., McManus, J. B., Shorter, J. H., Canagaratnam, M. R., Onasch, T. B., and Kolb, C. E.: Characterization of urban pollutant emission fluxes and ambient concentration distributions using a mobile laboratory with rapid response instrumentation, Faraday Discuss., 130, 327-339, doi:10.1039/B500411J, 2005.

Hönninger, G., von Friedeburg, C., and Platt, U.: Multi axis differential optical absorption spectroscopy (MAX-DOAS), Atmos. Chem. Phys., 4, 231-254, doi:10.5194/acp-4-231-2004, 2004.

Houweling, S., Dentener, F., and Lelieveld, J.: The impact of nonmethane hydrocarbon compounds on tropospheric photochemistry, J. Geophys. Res.-Atmos., 103, 10673-10696, doi:10.1029/97JD03582, 1998.

Inomata, S., Tanimoto, H., Kameyama, S., Tsunogai, U., Irie, H., Kanaya, Y., and Wang, Z.: Technical Note: Determination of formaldehyde mixing ratios in air with PTR-MS: laboratory experiments and field measurements, Atmos. Chem. Phys., 8, 273284, doi:10.5194/acp-8-273-2008, 2008.

Irie, H., Takashima, H., Kanaya, Y., Boersma, K. F., Gast, L., Wittrock, F., Brunner, D., Zhou, Y., and Van Roozendael, M.: Eightcomponent retrievals from ground-based MAX-DOAS observations, Atmos. Meas. Tech., 4, 1027-1044, doi:10.5194/amt-41027-2011, 2011.

Jacquemart, D., Laraia, A., Kwabia Tchana, F., Gamache, R. R., Perrin, A., and Lacome, N.: Formaldehyde around 3.5 and 5.7- $\mu \mathrm{m}$ : Measurement and calculation of broadening coefficients, J. Quant. Spectrosc. Ra., 111, 1209-1222, doi:10.1016/j.jqsrt.2010.02.004, 2010.

Jenkin, M. E., Murrellis, T. P., and Passant, N. R.: The temporal dependence of ozone precursor emissions: estimation and appli- cation, AEA Technology, Report No. AEAT/R/ENV/0355, Issue $1,2000$.

Jones, N. B., Riedel, K., Allan, W., Wood, S., Palmer, P. I., Chance, K., and Notholt, J.: Long-term tropospheric formaldehyde concentrations deduced from ground-based fourier transform solar infrared measurements, Atmos. Chem. Phys., 9, 7131-7142, doi:10.5194/acp-9-7131-2009, 2009.

Kanakidou, M., Seinfeld, J. H., Pandis, S. N., Barnes, I., Dentener, F. J., Facchini, M. C., Van Dingenen, R., Ervens, B., Nenes, A., Nielsen, C. J., Swietlicki, E., Putaud, J. P., Balkanski, Y., Fuzzi, S., Horth, J., Moortgat, G. K., Winterhalter, R., Myhre, C. E. L., Tsigaridis, K., Vignati, E., Stephanou, E. G., and Wilson, J.: Organic aerosol and global climate modelling: a review, Atmos. Chem. Phys., 5, 1053-1123, doi:10.5194/acp-5-1053-2005, 2005.

Koelemeijer, R. B. A., de Haan, J. F., and Stammes, P.: A database of spectral surface reflectivity in the range $335-772 \mathrm{~nm}$ derived from 5.5 years of GOME observations, J. Geophys. Res., 108, 4070, doi:10.1029/2002JD002429, 2003.

Li, Y. S., Campana, M., Reimann, S., Schaub, D., Stemmler, K., Staehelin, J., and Thomas, P. T.: Hydrocarbon concentrations at the Alpine mountain sites Jungfraujoch and Arosa, Atmos. Environ., 39, 1113-1127, doi:10.1016/j.atmosenv.2004.09.084, 2005.

Legreid, G., Folini, D., Staehelin, J., Balzani Lööv, J., Steinbacher, M., and Reimann, S.: Measurements of organic trace gases including oxygenated volatile organic compounds at the high alpine site Jungfraujoch (Switzerland): seasonal variation and source allocations, J. Geophys. Res., 113, D05307, doi:10.1029/2007JD008653, 2008.

Lee, M., Heikes, B. G., Jacob, D. J., Sachse, G., and Anderson, B.: Hydrogen peroxide, organic hydroperoxide, and formaldehyde as primary pollutants from biomass burning, J. Geophys. Res., 102, 1301-1309, doi:10.1029/96JD01709, 1997.

Lee, Y. N., Zhou, X., Kleinman, L. I., Nunnermacker, L. J., Springston, S. R., Daum, P. H., Newman, L., Keigley, W. G., Holdren, M. W., Spicer, C. W., Young, V., Fu, B., Parrish, D. D., Holloway, J., Williams, J., Roberts, J. M., Ryerson, T. B., and Fehsenfeld, F. C.: Atmospheric chemistry and distribution of formaldehyde and several multioxygenated carbonyl compounds during the 1995 Nashville Middle Tennessee Ozone Study, J. Geophys. Res.-Atmos., 103, 22449-22462, doi:10.1029/98JD01251, 1998.

Logan, J. A., Prather, M. J., Wofsy, S. C., and McElroy, M. B.: Tropospheric chemistry: a global perspective, J. Geophys. Res., 86, 7210-7254, doi:10.1029/JC086iC08p07210, 1981.

Lugauer, M., Baltensperger, U., Furger, M., Gäggeler, H. W., Jost, D. T., Nyeki, S., and Schwikowski, M.: Influences of vertical transport and scavenging on aerosol particle surface area and radon decay product concentrations at the Jungfraujoch (3454 ma.s.1.), J. Geophys. Res., 105, 1986-19879, doi:10.1029/2000JD900184, 2000.

Mao, J., Jacob, D. J., Evans, M. J., Olson, J. R., Ren, X., Brune, W. H., Clair, J. M. St., Crounse, J. D., Spencer, K. M., Beaver, M. R., Wennberg, P. O., Cubison, M. J., Jimenez, J. L., Fried, A., Weibring, P., Walega, J. G., Hall, S. R., Weinheimer, A. J., Cohen, R. C., Chen, G., Crawford, J. H., McNaughton, C., Clarke, A. D., Jaeglé, L., Fisher, J. A., Yantosca, R. M., Le Sager, P., and Carouge, $\mathrm{C}$. Chemistry of hydrogen oxide radicals $\left(\mathrm{HO}_{\mathrm{x}}\right)$ in 
the Arctic troposphere in spring, Atmos. Chem. Phys., 10, 58235838, doi:10.5194/acp-10-5823-2010, 2010.

Mao, J., Paulot, F., Jacob, D. J., Cohen, R. C., Crounse, J. D., Wennberg, P. O., Keller, C. A., Hudman, R. C., Barkley, M. P., and Horowitz, L. W.: Ozone and organic nitrates over the eastern United States: Sensitivity to isoprene chemistry, J. Geophys. Res.-Atmos., 118, 11,256-268, doi:10.1002/jgrd.50817, 2013.

Meller, R. and Moortgat, G. K.: Temperature dependence of the absorption cross sections of formaldehyde between 223 and $323 \mathrm{~K}$ in the wavelength range $225-375 \mathrm{~nm}$, J. Geophys. Res., 105, 7089-7101, 2000.

Notholt, J., Toon, G., Stordal, F., Solberg, S., Schmidbauer, N., Becker, E., Meier, A., and Sen, B.: Seasonal variations of atmospheric trace gases in the high Arctic at $79^{\circ}$ N, J. Geophys. Res., 102, 12855-12861, doi:10.1029/97JD00337, 1997.

Park, R. J., Jacob, D. J., Field, B. D., Yantosca, R. M., and Chin, M.: Natural and transboundary pollution influences on sulfate-nitrate-ammonium aerosols in the United States: implications for policy, J. Geophys. Res., 109, D15204, doi:10.1029/2003JD004473, 2004.

Peeters, J. and Müller, J.-F.: $\mathrm{HO}_{x}$ radical regeneration in isoprene oxidation via peroxy radical isomerisations. II: Experimental evidence and global impact, Phys. Chem. Chem. Phys., 12, 1422714235, 2010.

Peeters, J., Müller, J.-F., Stavrakou, T., and Nguyen, S. V.: Hydroxyl radical recycling in isoprene oxidation driven by hydrogen bonding and hydrogen tunneling: the upgraded LIM1 mechanism, J. Phys. Chem., 118, 8625-8643, doi:10.1021/jp5033146, 2014.

Perrin, A., Jacquemart, D., Kwabia Tchanab, F., and Lacome, N.: Absolute line intensities measurements and calculations for the 5.7 and $3.6 \mu \mathrm{m}$ bands of formaldehyde, J. Quant. Spectrosc. Ra., 110, 700-716, doi:10.1016/j.jqsrt.2008.11.005, 2009.

Pikelnaya, O., Hurlock, S. C., Trick, S., and Stutz, J.: Intercomparison of multiaxis and long-path optical absorption spectroscopy measurements in the marine boundary layer, J. Geophys. Res., 112, D10S01, doi:10.1029/2006JD007727, 2007.

Pinardi, G., Van Roozendael, M., Abuhassan, N., Adams, C., Cede, A., Clémer, K., Fayt, C., Frieß, U., Gil, M., Herman, J., Hermans, C., Hendrick, F., Irie, H., Merlaud, A., Navarro Comas, M., Peters, E., Piters, A. J. M., Puentedura, O., Richter, A., Schönhardt, A., Shaiganfar, R., Spinei, E., Strong, K., Takashima, H., Vrekoussis, M., Wagner, T., Wittrock, F., and Yilmaz, S.: MAXDOAS formaldehyde slant column measurements during CINDI: intercomparison and analysis improvement, Atmos. Meas. Tech., 6, 167-185, doi:10.5194/amt-6-167-2013, 2013.

Platt, U. and Stutz, J.: Differential Optical Absorption Spectroscopy (DOAS): principles and Applications, ISBN 978-3-540-21193-8, Springer, Berlin-Heidelberg, Germany, 2008.

Possanzini, M., Di Palo, V., and Ceccinato, A.: Sources and photodecomposition of formaldehyde and acetaldehyde in Rome ambient air, Atmos. Environ., 36, 3195-3201, doi:10.1016/S13522310(02)00192-9, 2002.

Puķīte, J., Kühl, S., Deutschmann, T., Platt, U., and Wagner, T.: Extending differential optical absorption spectroscopy for limb measurements in the UV, Atmos. Meas. Tech., 3, 631-653, doi:10.5194/amt-3-631-2010, 2010.

Reimann, S., Schaub, D., Stemmler, K., Folini, D., Hill, M., Hofer, P., Buchmann, B., Simmonds, P. G., Greally, B. R., and O'Doherty, S.: Halogenated greenhouse gases at the Swiss High
Alpine Site of Jungfraujoch (3580 ma.s.1.): continuous measurements and their use for regional European source allocation, J. Geophys. Res., 109, D05307, doi:10.1029/2003JD003923, 2004.

Rinsland, C. P., Jones, N. B., Connor, B. J., Logan, J. A., Pougatchev, N. S., Goldman, A., Murcray, F. J., Stephen, T. M., Pine, A. S., Zander, R., Mahieu, E., and Demoulin, P.: Northern and Southern Hemisphere ground-based infrared spectroscopic measurements of tropospheric carbon monoxide and ethane, J. Geophys. Res., 103, 28197-28217, doi:10.1029/98JD02515, 1998.

Rodgers, C. D.: Inverse Methods for Atmospheric Sounding: Theory and Practice, Series on Atmospheric, Oceanic and Planetary Physics, Vol. 2, World Scientific Publishing Co., Singapore, 2000.

Rodgers, C. D. and Connor, B. J.: Intercomparison of remote sounding instruments, J. Geophys. Res., 108, 4116-4129, doi:10.1029/2002JD002299, 2003.

Rothman, L. S.: AFGL Atmospheric absorption line parameters compilation: 1980 version, Appl. Optics, 20, 791-795, doi:10.1021/jp5033146, 1981.

Rothman, L. S., Gordon, I. E., Barbe, A., Benner, D. C., Bernath, P. F., Birk, M., Boudon, V., Brown, L. R., Campargue, A., Champion, J.-P., Chance, K., Coudert, L. H., Danaj, V., Devi, V. M., Fally, S., Flaud, J.-M., Gamache, R. R., Goldmanm, A., Jacquemart, D., Kleiner, I., Lacome, N., Lafferty, W. J., Mandin, J.-Y., Massie, S. T., Mikhailenko, S. N., Miller, C. E., Moazzen-Ahmadi, N., Naumenko, O. V., Nikitin, A. V., Orphal, J., Perevalov, V. I., Perrin, A., PredoiCross, A., Rinsland, C. P., Rotger, M., Simeckova, M., Smith, M. A. H., Sung, K., Tashkun, S. A., Tennyson, J., Toth, R. A., Vandaele, A. C., and Vander Auwera, J.: The Hitran 2008 molecular spectroscopic database, J. Quant. Spectrosc. Ra., 110, 533-572, doi:10.1016/j.jqsrt.2009.02.013, 2009.

Rothman, L. S., Gordon, I. E., Babikov, Y., Barbe, A., Chris Benner, D., Bernath, P. F., Birk, M., Bizzocchi, L., Boudon, V., Brown, L. R., Campargue, A., Chance, K., Cohen, E. A., Coudert, L. H., Devi, V. M., Drouin, B. J., Fayt, A., Flaud, J.M., Gamache, R. R., Harrison, J. J., Hartmann, J.-M., Hill, C., Hodges, J. T., Jacquemart, D., Jolly, A., Lamouroux, J., Le Roy, R. J., Li, G., Long, D. A., Lyulin, O. M., Mackie, C. J., Massie, S. T., Mikhailenko, S., Müller, H. S. P., Naumenko, O. V., Nikitin, A. V., Orphal, J., Perevalov, V., Perrin, A., Polovtseva, E. R., Richard, C., Smith, M. A. H., Starikova, E., Sung, K., Tashkun, S., Tennyson, J., Toon, G. C., Tyuterev, V1. G., and Wagner, G.: The HITRAN2012 molecular spectroscopic database, J. Quant. Spectrosc. Ra., 130, 4-50, doi:10.1016/j.jqsrt.2013.07.002, 2013.

Schultz, M. G., Backman, L., Balkanski, Y., Bjoerndalsaeter, S., Brand, R., Burrows, J. P., Dalsøren, S., de Vasconcelos, L., Grodtmann, B., Hauglustaine, D. A., Heil, A., Hoelzemann, J. J., Isaksen, I. S. A., Kaurola, J., Knorr, W., LadstaetterWeißenmayer, A., Mota, B., Oom, D., Pacyna, J., Panasiuk, D., Pereira, J. M. C., Pulles, T., Pyle, J., Rast, S., Richter, A., Savage, N., Scnadt, C., Schulz, M., Spessa, A., Staehelin, J., Sundet, J. K., Szopa, S., Thonicke, K., van het Bolscher, M., van Noije, T., van Velthoven, P., Vik, A. F., and Wittrock, F.: REanalysis of the TROpospheric chemical composition of the past 40 years (RETRO): a long-term global modeling study of tropospheric chemistry, Jülich/Hamburg, Germany, 48/2007 report 
on Earth System Science of the Max Planck Institute for Meteorology, Hamburg, Germany, ISSN 1614-1199, available at: http://retro.enes.org (last access: 17 July 2014), 2007.

Shettle, E. P.: Models of aerosols, clouds, and precipitation for atmospheric propagation studies, in: NATO AGARD Conference Proceedings No. 454: Atmospheric propagation in the UV, visible, IR and mm-region and related system aspects, 9-13 October 1989, Neuilly sur Seine, France, 1989.

Simpson, D., Michael Gauss, S. T., and Valdebenito, A.: Model Updates Transboundary acidification, eutrophication and ground level ozone in Europe EMEP Status Report 1/2010, The Norwegian Meteorological Institute, Oslo, Norway, 2010.

Spurr, R., LIDORT and VLIDORT: Linearized Pseudo-Spherical Scalar and Vector Discrete Ordinate Radiative Transfer Models for Use in Remote Sensing Retrieval Problems, Light Scattering Reviews, Vol. 3, edited by: Kokhanovsky, A., Springer, Berlin Heidelberg, Germany, 2008.

Sussmann, R., Borsdorff, T., Rettinger, M., Camy-Peyret, C., Demoulin, P., Duchatelet, P., Mahieu, E., and Servais, C.: Technical Note: Harmonized retrieval of column-integrated atmospheric water vapor from the FTIR network - first examples for longterm records and station trends, Atmos. Chem. Phys., 9, 89878999, doi:10.5194/acp-9-8987-2009, 2009.

Staffelbach, T., Neftel, A., Stauffer, B., and Jacob, D. J.: A record of the atmospheric methane sink from formaldehyde in polar ice cores, Nature, 349, 603-605, doi:10.1038/349603a0, 1991.

Starokozhev, E., Fries, E., Cycura, A., and Püttmann, W.: Distribution of VOCs between air and snow at the Jungfraujoch high alpine research station, Switzerland, during CLACE 5 (winter 2006), Atmos. Chem. Phys., 9, 3197-3207, doi:10.5194/acp-93197-2009, 2009.

Stavrakou, T., Müller, J.-F., De Smedt, I., Van Roozendael, M., van der Werf, G. R., Giglio, L., and Guenther, A.: Global emissions of non-methane hydrocarbons deduced from SCIAMACHY formaldehyde columns through 2003-2006, Atmos. Chem. Phys., 9, 3663-3679, doi:10.5194/acp-9-3663-2009, 2009a.

Stavrakou, T., Müller, J.-F., De Smedt, I., Van Roozendael, M., van der Werf, G. R., Giglio, L., and Guenther, A.: Evaluating the performance of pyrogenic and biogenic emission inventories against one decade of space-based formaldehyde columns, Atmos. Chem. Phys., 9, 1037-1060, doi:10.5194/acp-9-1037-2009, 2009b.

Stavrakou, T., Guenther, A., Razavi, A., Clarisse, L., Clerbaux, C., Coheur, P.-F., Hurtmans, D., Karagulian, F., De Mazière, M., Vigouroux, C., Amelynck, C., Schoon, N., Laffineur, Q., Heinesch, B., Aubinet, M., Rinsland, C., and Müller, J.-F.: First space-based derivation of the global atmospheric methanol emission fluxes, Atmos. Chem. Phys., 11, 4873-4898, doi:10.5194/acp-11-4873-2011, 2011.

Stavrakou, T., Müller, J.-F., Boersma, K. F., van der A, R. J., Kurokawa, J., Ohara, T., and Zhang, Q.: Key chemical $\mathrm{NO}_{\mathrm{x}}$ sink uncertainties and how they influence top-down emissions of nitrogen oxides, Atmos. Chem. Phys., 13, 9057-9082, doi:10.5194/acp-13-9057-2013, 2013.

Stavrakou, T., Müller, J.-F., Bauwens, M., De Smedt, I., Van Roozendael, M., Guenther, A., Wild, M., and Xia, X.: Isoprene emissions over Asia 1979-2012: impact of climate and land-use changes, Atmos. Chem. Phys., 14, 4587-4605, doi:10.5194/acp14-4587-2014, 2014.
Stickler, A., Fischer, H., Williams, J., de Reus, M., Sander, R., Lawrence, M. G., Crowley, J. N., and Lelieveld, J.: Influence of summertime deep convection on formaldehyde in the middle and upper troposphere over Europe, J. Geophys. Res., 111, D14308, doi:10.1029/2005JD007001, 2006.

Tan, D., Faloona, I., Simpas, J. B., Brune, W., Shepson, P. B., Couch, T. L., Sumner, A. L., Carroll, M. A., Thornberry, T., Apel, E., Riemer, D., and Stockwell, W.: $\mathrm{HO}_{x}$ budgets in a deciduous forest: results from the PROPHET summer 1998 campaign, J. Geophys. Res.-Atmos., 106, 24407-24427, doi:10.1029/2001JD900016, 2001.

Tejwani, G. D. T. and Yeung, E. S.: Pressure-broadened linewidths of formaldehyde, J. Chem. Phys., 66, 4915-4918, doi:10.1063/1.433830, 1977.

Thalman, R. and Volkamer, R.: Temperature dependent absorption cross-sections of $\mathrm{O}_{2}-\mathrm{O}_{2}$ collision pairs between 340 and $630 \mathrm{~nm}$ at atmospherically relevant pressure, Phys. Chem. Chem. Phys., 15, 15371-15381, doi:10.1039/C3CP50968K, 2013.

Vandaele, A. C., Hermans, C., Simon, P. C., Carleer, M., Colin, R., Fally, S., Merienne, M.-F., Jenouvrier, A., and Coquart, B.: Measurements of the $\mathrm{NO}_{2}$ absorption crosssection from $42000 \mathrm{~cm}^{-1}$ to $10000 \mathrm{~cm}^{-1}(238-1000 \mathrm{~nm})$ at $220 \mathrm{~K}$ and $294 \mathrm{~K}$, J. Quant. Spectrosc. Ra., 59, 171-184, doi:10.1016/S0022-4073(97)00168-4, 1998.

van der Werf, G. R., Randerson, J. T., Giglio, L., Collatz, G. J., Mu, M., Kasibhatla, P. S., Morton, D. C., DeFries, R. S., Jin, Y., and van Leeuwen, T. T.: Global fire emissions and the contribution of deforestation, savanna, forest, agricultural, and peat fires (19972009), Atmos. Chem. Phys., 10, 11707-11735, doi:10.5194/acp10-11707-2010, 2010.

van Donkelaar, A., Martin, R. V., Leaitch, W. R., Macdonald, A. M., Walker, T. W., Streets, D. G., Zhang, Q., Dunlea, E. J., Jimenez, J. L., Dibb, J. E., Huey, L. G., Weber, R., and Andreae, M. O.: Analysis of aircraft and satellite measurements from the Intercontinental Chemical Transport Experiment (INTEX-B) to quantify long-range transport of East Asian sulfur to Canada, Atmos. Chem. Phys., 8, 2999-3014, doi:10.5194/acp-8-2999-2008, 2008.

Viatte, C., Strong, K., Walker, K. A., and Drummond, J. R.: Five years of $\mathrm{CO}, \mathrm{HCN}, \mathrm{C}_{2} \mathrm{H}_{6}, \mathrm{C}_{2} \mathrm{H}_{2}, \mathrm{CH}_{3} \mathrm{OH}, \mathrm{HCOOH}$ and $\mathrm{H}_{2} \mathrm{CO}$ total columns measured in the Canadian high Arctic, Atmos. Meas. Tech., 7, 1547-1570, doi:10.5194/amt-7-1547-2014, 2014.

Vigouroux, C., Hendrick, F., Stavrakou, T., Dils, B., De Smedt, I., Hermans, C., Merlaud, A., Scolas, F., Senten, C., Vanhaelewyn, G., Fally, S., Carleer, M., Metzger, J.-M., Müller, J.-F., Van Roozendael, M., and De Mazière, M.: Ground-based FTIR and MAX-DOAS observations of formaldehyde at Réunion Island and comparisons with satellite and model data, Atmos. Chem. Phys., 9, 9523-9544, doi:10.5194/acp-9-9523-2009, 2009.

Wagner, T., Dix, B., von Friedeburg, C., Friess, U., Sanghavi, S., Sinreich, R., and Platt, U.: MAX-DOAS $\mathrm{O}_{4}$ measurements: A new technique to derive information on atmospheric aerosols - principles and information content, J. Geophys. Res., 109, D22205, doi:10.1029/2004jd004904, 2004.

Wagner, T., Deutschmann, T., and Platt, U.: Determination of aerosol properties from MAX-DOAS observations of the Ring effect, Atmos. Meas. Tech., 2, 495-512, doi:10.5194/amt-2-4952009, 2009. 
Wagner, T., Beirle, S., Brauers, T., Deutschmann, T., Frieß, U., Hak, C., Halla, J. D., Heue, K. P., Junkermann, W., Li, X., Platt, U., and Pundt-Gruber, I.: Inversion of tropospheric profiles of aerosol extinction and $\mathrm{HCHO}$ and $\mathrm{NO}_{2}$ mixing ratios from MAX-DOAS observations in Milano during the summer of 2003 and comparison with independent data sets, Atmos. Meas. Tech., 4, 2685-2715, doi:10.5194/amt-4-2685-2011, 2011.

Wang, T., Hendrick, F., Wang, P., Tang, G., Clémer, K., Yu, H., Fayt, C., Hermans, C., Gielen, C., Müller, J.-F., Pinardi, G., Theys, N., Brenot, H., and Van Roozendael, M.: Evaluation of tropospheric $\mathrm{SO}_{2}$ retrieved from MAX-DOAS measurements in Xianghe, China, Atmos. Chem. Phys., 14, 11149-11164, doi:10.5194/acp14-11149-2014, 2014.

Wittrock, F., Richter, A., Oetjen, H., Burrows, J. P., Kanakidou, M., Myriokefalitakis, S., Volkamer, R., Beirle, S., Platt, U., and Wagner, T.: Simultaneous global observations of glyoxal and formaldehyde from space, Geophys. Res. Lett., 33, L16804, doi:10.1029/2006GL026310, 2006.
Xiao, Y., Logan, J. A., Jacob, D. J., Hudman, R. C., Yantosca, R., and Blake, D. R.: Global budget of ethane and regional constraints on U. S. sources, J. Geophys. Res., 113, D21306, doi:10.1029/2007JD009415, 2008.

Zander, R., Mahieu, E., Demoulin, P., Duchatelet, P., Roland, G., Servais, C., Mazière, M. D., Reimann, S., and Rinsland, C. P.: Our changing atmosphere: evidence based on long-term infrared solar observations at the Jungfraujoch since 1950, Sci. Total Environ., 391, 184-195, doi:10.1016/j.scitotenv.2007.10.018, 2008.

Zellweger, C., Forrer, J., Hofer, P., Nyeki, S., Schwarzenbach, B., Weingartner, E., Ammann, M., and Baltensperger, U.: Partitioning of reactive nitrogen $\left(\mathrm{NO}_{\mathrm{y}}\right)$ and dependence on meteorological conditions in the lower free troposphere, Atmos. Chem. Phys., 3, 779-796, doi:10.5194/acp-3-779-2003, 2003. 